\title{
SEMANTIC IMAgINATION AS CONDITION TO OUR LINGUISTIC EXPERIENCE
}

\author{
NAZARENo EdUARDo DE AlmeidA
}

\begin{abstract}
The main purpose of this article is, from a semiotic perspective, arguing for the recognizing of a semantic role of the imagination as a necessary condition to our linguistic experience, regarded as an essential feature of the relations of our thought with the world through signification processes (and the sign systems they perform); processes centered in but not reducible to discourse. The text is divided into three parts. The first part presents the traditional position in philosophy and cognitive sciences that had barred until recent times the possibility to investigate the semantic function performed by imagination, mainly due to the anti-psychologist arguments on which it is based. After that, I situate my perspective inside of the recent research panorama in philosophy and cognitive science. The second part presents the semiotic framework on the relation between thought, language, and world, conceived through the concepts of signification processes and sense-conditions. Within this framework, I introduce the concept of linguistic experience, characterizing semantic imagination as one of its sense-conditions. In the third part, several pieces of evidence for corroborating the semantic function of imagination are discussed. These pieces come from the fields of phenomena denoted as diagrammatic thought and counterfactual thought. Diagrammatic thought, briefly discussed, points out the semantic work of imagination in the semi-discursive sign systems constructed in mathematics, logic, and natural science. After defending a widening of the concept of counterfactual thought, and its intrinsic relation with semantic imagination, the role of semantic imagination is briefly discussed in some types of counterfactual thought found in our conceptions of modal concepts, in thought experiments, in apagogical arguments, and in the creative discursive devices.
\end{abstract}

Keywords: Semantics; imagination; linguistic experience.

"What is now proved was once only imagined"

William Blake, Proverbs of Hell

\section{Critical prologue: removing some hindrances and situating the present perspective to introduce the concept of semantic imagination}

Before introducing the concept of semantic imagination and presenting the more direct pieces of evidence to corroborate it as a necessary condition to our linguistic

Principia 21(3): 339-378 (2017).

Published by NEL — Epistemology and Logic Research Group, Federal University of Santa Catarina (UFSC), Brazil. 
experience, we need to expose in general lines the traditional position in philosophy and psychology that had blocked the way through which this concept can make sense.

From such standpoint, the expression 'semantic imagination' would be a kind of oxymoron like 'round square' or 'cold fire'. This supposedly is so because the name 'imagination' could only denote a mental capacity whose treatment is a task of the psychology, philosophy of mind or even epistemology. On the other side, the adjective 'semantic' could only denote the logic and linguistic concept of meaning, whose approach is the task of the philosophy of language, philosophy of logic, philosophical logic or linguistics. Thus, the expression 'semantic imagination' could not denote the unity of a concept. Rather, it would indicate a conceptual or category mistake. This diagnosis is based upon the general and until recently dominant thesis in philosophy and cognitive sciences according to which imagination should be taken as an essentially non-linguistic mental capacity. Such traditional tenet claims that imagination could only fill with mental (or even with extra-mental) images the propositional content of our linguistic expressions. In a didactic metaphor, imagination should only illustrate with personal and subjective colors and pictures those things that are objectively presented by propositions for any rational being.

This thesis was drawn up in the passage from the nineteenth to the twentiethcentury philosophy, in the critical arguments elaborated by Frege, Russell, and Husserl against what was called 'psychologism'. ${ }^{1}$ In the particular case of the imagination, Frege's anti-psychologist arguments suppose it as a general feature of subjective representation (Vorstellung), which should be rigorously detached from the objective sense (Sinn) underlying the sentences (Sätze) of the natural language, but chiefly of the scientific and formal languages. ${ }^{2}$ According to the early Husserl, imagination would be restrained to fill the ideally meaningful logical and conceptual structures with psychological and subjective content without touching the meaning (Bedeutung) of these structures, a meaning that is not altered in applying such structures to the phenomenal content of the experience. ${ }^{3}$ In both cases, imagination does not reach in any way the level of the meaning.

Before continuing, it is important to say that my proposal to introduce the concept of semantic imagination is no way committed to the untenable psychologist position, understood as the attempt to reduce the meaning of the logical and mathematical structures and laws to psychological structures and laws. On this aspect, anti-psychologist arguments are still valid. However, the use of these arguments to ground a kind of anti-psychologist reductionism, according to which meaning has not to do with psychological and mental factors, is as untenable as the psychologist position refuted by them. As the old Aristotelian theory of argumentation already teaches us, refuting a general position is not sufficient to justify the adoption of the contrary general position. Thus, anti-psychologist arguments miss completely the point when taken as the ground of a general theory of meaning. ${ }^{4}$ The proposal of the concept 
of semantic imagination (alongside the semiotic theoretical framework to which it belongs) attempts precisely to avoid these extreme positions. ${ }^{5}$

Notwithstanding this general problem with the anti-psychologist arguments about meaning, the exclusion of the imagination promoted by them was incorporated in the early history of the cognitive models and was assumed by many leading pioneers in this new scientific paradigm. Those arguments turned out to be adopted by the early cognitive scientists in their distinction between two supposedly different levels of the mental processes: the propositional level (roughly corresponding to the level of language and meaning) and the imagery level (roughly corresponding to the level of perception, memory, and imagination). Such an adoption was due to the fact these researchers assumed the logically oriented computational model of the mind. Summing up the debate headed by Pylyshyn and Kosslyn from the early seventies of the past century until recent times, the place and role of the imagination in the mental life was restrained to the question whether mental processes are exclusively conducted by means of the propositional level of mind or there would be also some processes that are carried out primarily and/or exclusively by means of the imagery level. That is, whether mental processes would be carried out only by the propositional level of the mind or there would be some space and cases in which the imagery level would take the command of the mental processes. ${ }^{6}$ Whatever be the position taken in this debate, within such a model the concept of meaning remains attached to the propositional level of the mind (implicitly restrained to the logically structured mental language or 'mentalese') and would have nothing to do with the imagery level (implicitly restrained to visual-oriented imagining and remembering). Ironically, the distinction by genre between the logical structured sense of the sentences and the psychological imagery content of the mental representation elaborated by anti-psychologist philosophers enter in a decisive way in the early development of the cognitive psychology.

This picture began to change from the early eighties of the past century when cognitive scientists introduced in their researches the concepts of propositional memory and semantic memory, ${ }^{7}$ as well as by the recent development of an interdisciplinary and anti-Cartesian research program congregating the efforts of linguists, psychologists, and philosophers around the general conception according to which mind, language, and cognition are embedded in a body and in environmental situations, distributed through different people and times, so as extended to extra-corporeal artifacts and social artifices. Within this new theoretical panorama, mental capacities once banned by the traditional model above indicated begin to be seen as important factors that have to do with our constitution of the meaning.

For more than a decade, I am developing a comprehensive conceptual model to investigate the relation between thought, language, and world in a semiotic perspective allied with the research program just mentioned. ${ }^{8}$ Within such model, I came to 
elaborated the hypothesis according to which imagination (in its synergic cooperation with perception and memory) is a necessary condition to the signification processes in which thought is related to world through sign systems. ${ }^{9}$ Thus, imagination is seen as a condition towards a more empirically adequate understanding of how we give sense to our linguistic experience, which is centered in the discursive sign system, though not confined to it. Nevertheless, cognitive and philosophical researches on imagination into this new theoretical horizon are very recent and in growing development. ${ }^{10}$ At this point, I believe my proposal of recognizing a semantic function of imagination can philosophically contribute to constituting a more suitable conceptual framework that reinforces the need for further researches in this field, both on the empirical side of cognitive sciences and on the conceptual side of philosophy.

\section{Introducing semantic imagination: the thought-language-world relation from a semiotic point of view and the characterization of the linguistic experience}

Once done the due presentations, we can now introduce the concept of semantic imagination within the conceptual framework in which it is required. In a general manner, this concept is part of a philosophical perspective whose general goal is to investigate the conditions that make possible the plurality of forms in which the relation between thought, language, and world is carried out. ${ }^{11}$ This general conceptual framework is built upon several sources and insights but is mainly guided by some fundamental tenets coming from Peirce's semiotics. ${ }^{12}$ Semiotics, in its Peircean version, is a general theory about semiosis. On its turn, semiosis is defined as the inferential process in which anything taken as a sign refers to something in the world in some sense for someone. Regarded as a kind of semiosis, ${ }^{13}$ the thought-language-world relation can be investigated by means of the concept of signification, understood as the open set of processes performed by us through sign systems in order to constitute meaning to our life forms and to the world in which we inhabit. ${ }^{14}$ Regarded this way, it is quite clear that the concept of signification is not equivalent to the traditional concept of meaning. In a vague but intuitive manner, we can characterize signification as an open set of processes through which human life and the world we inhabit in can "make sense" to us, that is, the processes through which we generate, convey, and transform the meaning of our life forms and of the world we live in.

As we can see from this initial characterization, the fundamental concept through which this perspective approaches the thought-language-world relation as signification is that embedded in the common notions of 'making sense' or 'having (some/a) sense', and not, as in the dominant view, by means of the concept of truth. ${ }^{15}$ What such dominant view systematically overlooks is that making or having sense is a ba-

Principia 21(2): 339-378 (2017). 
sic and previous condition to anything that can count as a bearer of a truth-value, as well as that many meaningful (discursive or non-discursive) structures have no truth-value at all. ${ }^{16}$ Thus, even if many philosophers already have made use of the concept of meaning to analyze the thought-language-world relation, such concept is usually understood either based on or necessarily directed to the concept of truth. This is particularly evident by the widespread conception according to which meaning, whatever be its definition or extent, must be investigated linked to what is now called truth-conditions, which are primarily instantiated in indicative sentences or declarative discourse. Therefore, the thought-language-world relation came to be conceived as a truth-oriented relation, so as it is usually understood and investigated as a relation between a rational, internal, and representational mind, whose primary goal is the construction or discovery of knowledge about objective reality symbolically encoded in a systematically organized corpus of logically structured declarative discourse, which, at its best state, can acquire the status of science. Disregarding the somewhat caricatured physiognomy of this description, it is hard to overestimate the power of this model. Its origins can be tracked back into Greek philosophy, although its modern version has been shaped from Descartes onward. In fact, even modern ethics, and aesthetics, which emphasize the importance of the concepts of good and beauty in the human life and social world came to be constituted closely linked to this model. ${ }^{17}$

In contrast with this traditional model, the task of the present perspective is to approach the thought-language-world relation through the concept of signification, and the concept of signification through what we can call the sense-conditions instantiated in any sign system from which meaning can arise as an emergent property. Meaning, therefore, is not some kind of perennial property displayed in an ideally well-formed declarative discourse (or formal system) expressing a somehow eternal or timeless propositional content, but a property that emerges from the complex interaction between the sense ("thought") and the reference ("world") of the signs conjoined in mutable sign systems ("language") operated by us. Discourse, for sure, performs a central role among sign systems. ${ }^{18}$ However, discourse is neither primarily declarative discourse - rather it is primarily dialogue and narrative - nor is a self-contained and independent system, but an open and dynamic system, which is entangled in their contexts of use and with other sign systems.

From this generic observations, we can describe the more general structure supposed under the concept of signification as being instantiated in three modes of relation carried out through sign systems: (i) the relation with ourselves as individuals; (ii) our relation with other individuals and groups; and (iii) the relation we, as individuals and groups, maintain with the natural and historical world we inhabit in. In a single semiotic characterization, we can say that the thought-language-world relation consists in all our collective and individual forms to putting the world into work across

Principia 21(2): 339-378 (2017). 
meaningful structures (both material and abstract, discursive and non-discursive), making it a world at once individual and shared in the personal and collective cooperation of perception, memory, and imagination, a cooperation which forms what we denote, on the individual side, by the term 'personality', and on the collective side, by the term 'culture'. In this characterization, perception, memory, and imagination have the role of basic psychosomatic capacities that are grounding conditions for the signification processes performed by our thought and language in generating, maintaining, and transforming the meaning of the human life and of the world we inhabit in. ${ }^{19}$ Such synergic cooperation between perception, memory, and imagination in constituting the meaning of our conceptions of ourselves and of the world is to be viewed as being embedded in a body and in contexts, as well as being distributed across many persons and extended in the action (and interactional) systems and in the material and conceptual sign systems required in order to generate, maintain, and transform these same cooperative systems. ${ }^{20}$

Within this general semiotic framework, I would like to indicate that imagination (together with perception and memory) is a necessary sense-condition to our signification processes be capable to generate, convey, understand, and transform the meaning attached to signs and sign systems, attachment with we can call by the concept of linguistic experience. That is, imagination is a necessary condition for any sign and sign system makes or have sense. ${ }^{21}$ So conceived, imagination is a psychosomatic capacity acting directly in our processes of signification, that is, in the construction of the relation between the sense of a sign (and of the sign systems) and its reference, and thus, in the constitution of the meaning of our signification processes, particularly in the fundamental signification process generally called discourse. Discourse is the most basic, usual, and polyvalent sign system from which we can coordinate all the other sign systems with which we effectively "produce" the sense of our life forms in the world. It is precisely because discourse, so to say, deals with and thus cooperate with all other sign systems operated by us that the idealized view on it should be discarded as empirically inadequate. As already indicated above, discourse is chiefly performed as dialogue and narrative, and it is only within and, so to say, "after" such a dialogic and narrative performance that discourse can acquire the "purified" form of declarative discourse, in which deictic, indexical, ambiguous, and figurative expressions must be absent or completely regimented, what is not the case in everyday discourse which takes place in narrative and dialogic form. It is as dialogue and narrative that discourse really interacts with contextual factors as well as with other sign systems.

As the basic sign system from which we handle the other sign systems, discourse is at the core of what we are calling here 'linguistic experience'. If we accept that the discourse, as dialogue and narrative, usually takes place interacting with other sign systems, then the concept of linguistic experience is focused on discourse, though

Principia 21(2): 339-378 (2017). 
not restricted to it. As we will see below, diagrammatic thought cannot be reduced to discourse, even though cannot also be excluded from the wide range of the concept of linguistic experience. Disregarding for a moment these borderline cases, we can characterize linguistic experience centered in discourse as the domain in which the general conceptual schemes, encoded in semantic memory, are applied through the shared rules of a given discursive sign system in view to achieve some specific aim into a particular perceptual scenario effectively lived by the bearers and users of these schemes. It is across this adaptation of the general to perform specific aims into particular scenarios that the pieces of discourse we produce can make or have sense. In fact, discourse can only be produced and understood if it synthesizes in its "body" our particular experience with the general conceptual schemes and patterns "stored" in semantic memory. ${ }^{22}$ Thereby, linguistic experience in its bulk, as our ability to produce and understand discursive structures of any length, is always a synthesis of particular experience and general concepts. Thus, linguistic experience is at the middle-way between the silent unshared singularity of our present situations and the shared secured generality of our conceptual schemes, which make the bridge from a given past to a given but open future. Linguistic experience, hence, is neither pure experience nor pure conceptuality. ${ }^{23}$ In a straight expression, linguistic experience is experience mediated by and incorporated in the discourse (as well as in the other sign systems blended with or accessed through our discursive productions).

The real meaning of our discursive productions emerges only from this meeting between the particularity of our aims and situations and the generality of the conceptual schemes which frame discursive productions. ${ }^{24}$ The meaning of our effective discourse always occurs embedding itself in the transition of our situations, leaving behind a part of itself along with the lived space-time that was gone forever. Only memory can save some aspects of the past situations, engraving them in some kind of stenographic abbreviation, in which some shadows of our discursive deeds are retained too. The effective meaning of the most part of our discursive productions is ephemeral, fading down with our life. It is only weaving the fragile thread of the words, scattered in the particular situations, into the fabric of the narratives that our discursive deeds begin to become more memorable for ourselves and for the others. A huge step forward was given when human beings invented the arts of writing and reading (along with the development of other sign systems), for through writing and reading their own narratives, the multitude of wasted past words survived the mutable memory of the generations and the downfall of cultures, gaining a new kind of power to generate and convey meaning at distant places and times. The four known discursive competencies — speech and listening, writing and reading - show us the effective complexity in which our linguistic experience (centered in the discourse) is really immersed. Inside this outlook, semantic memory, as a fundamental factor of our linguistic experience, cannot be simply viewed as an individual, internal and 
subjective mental capacity, but as the wide and complex dimension of human life in which, through the mentioned four discursive competencies, the individual discursive deeds crisscross themselves with the collective history of a group, a community, a culture, and, ultimately, with the history of mankind. ${ }^{25}$

The well-recognized phenomena denoted by the concept of linguistic change (or language change) show us that linguistic experience does not mean just mechanically applying immutable concepts and categories, given forever and for everybody, onto transitory and ephemeral perceptual situations through inalterable schemes and rules. In the complex and multifarious process of giving sense to our lives and to the world we live in, linguistic change is a constant either on the individual side or on the collective side of our discursive productions. Therefrom, we can see that linguistic change comes in pair with linguistic creativity, which denotes the ways we variably apply, adapt, enhance, transform, and ultimately create new conceptual schemes linked to our discursive deeds, schemes crystallized into semantic memory during the signification processes through which we pursue peculiar aims inside of the natural and social environment we are immersed in. ${ }^{26}$ Within the complex space-time of our linguistic experience, the meaning of our discursive deeds is rather a matter of becoming than of being. Our discursive productions are guided by the conceptual schemes and grammatical patterns presently in vigor, but these same schemes and rules are continually changed through this process of use, and such remark is valid either to the process of the individual language acquisition and enhancement, or to the process of collective use of these schemes and rules.

It is precisely the grounding character played by linguistic creativity in our linguistic experience that allow us to introduce the concept of semantic imagination as a necessary counterpart of the semantic memory, as well as to the semantic contribution coming from perception, a contribution mostly visible in its filling with concrete meaning (sense and reference) the otherwise hollow indexical and deictic expressions which anchor the discourse in the situations of our goal-oriented actions and deeds. ${ }^{27}$ If the common and general association between creativity and imagination is acceptable as right, so we must recognize that behind linguistic creativity there must be some kind of work done by imagination. Based on such inference, we can advance that imagination is the sole widely recognized mental capacity able not only to undertake the application of the general schemes encoded in semantic memory to the particularity of the perceptual situations, but also is the capacity that can explain how semantic memory and perception undergo changes during the processes that form our linguistic experience. ${ }^{28}$

However, what is called linguistic change is just the tip of the iceberg of a much wider and complex set of changes that we can call generically 'semiotic change', denoting the construction, performance, and transformation of all human sign systems. ${ }^{29}$ Semiotic change reveals the creative work of semantic imagination going 
beyond the borders of the discursive sign system, relating the sense(s) of the signs with their referents not only in the discourse but also in all other sign systems with which discourse is mixed in our effective life. In fact, it is at this point that we can see the above-indicated broad sense of the concept of linguistic experience, inasmuch as discourse, in its primary form of dialogue and of narrative, is always blended with other sign systems. Hence, the relation between the sense(s) of a sign and its referents is a relation of an embodied, situated, and extended mind with a continuously re-classifiable world throughout dynamic and evolving sign systems. This framework allows us to explain in a conceptual level the sense-conditions that make possible the continuous semiotic change of the sign systems, and thus, to acquire a suitable philosophical approach to the problem of linguistic change as a fundamental feature of our linguistic experience, which, more broader conceived, can be called semiotic experience.

Therefore, in order to really understand and explain the role of imagination as one of sense-conditions to our linguistic experience, conceived as the core of our semiotic experience (through the processes of creating, operating, and changing the meaning of the signs and sign systems), it is necessary to insert linguistic experience within a general semiotic framework able to encompass the semantic aspect shared by discursive and non-discursive sign systems alike. From the semiotic point of view, there are three basic possible kinds of relationships between the sense(s) of the signs and their referents, a division expressed by the three basic kinds of signs that constitute any sign system made up and operated by human beings. These kinds of signs are: icons, which maintain some sort of similarity relation with their referents; indexes, which maintain some sort of causality or contiguity relation with their referents; and symbols, which maintain a habitual and abstract relation with their referents. However, past, present, and (most likely) future sign systems are effectively always a blend of these three basic sign types. Thus, instead of only pure icons, indexes, and symbols, we actually and usually have combinations of these three kinds, so as we customarily have not pure icons but indexical icons and symbolic icons; moreover, we regularly have not pure indexes but iconic indexes and symbolic indexes; finally, we generally have not pure symbols but iconic symbols and indexical symbols. $^{30}$

One important remark on this view on the nature and function of the signs, sign structures, and sign systems is that they are not clearly and rigidly separated from the effective world they signify. Signs, sign structures, and sign systems can only perform their real functions within the signification processes insofar as things and states of affairs are taken as the first level of signs. Otherwise, our daily and more advanced processes of inference would not be cognitive and meaningful processes, what is absurd. Such is more visible in the iconic and indexical level than in symbolic level of signification. Paraphrasing Baudelaire's expression, in his famous sonnet Corre- 
spondences, into our effective life the world (including ourselves within it) is a forest of signs. It is only at the symbolic level that we can establish a sharper separation between signs and things, so as iconic and indexical signs enter into a sign system when they acquire some degree of symbolic meaning. The 'type-token' conceptual pair, first introduced by Peirce's semiotics, helps us to understand these levels and degrees. Well-established sign systems are those in which signs or sign structures of iconic and indexical nature are taken as iconic and indexical symbols or as instances of symbols. In the case of the discursive system, at its morphological level, the iconic symbolic structures are mostly those embedded in the rhetorical figures, and the indexical symbolic structures are those classified as deictic terms and expressions. ${ }^{31}$ After this remark, we can continue our path.

The functions of recognizing, constructing, reconstructing, and transforming the similarity, the contiguity and causality, as well as the habitual general and abstract content which are instantiated respectively in icons, indexes, and symbols (as well as in the more usual blends of them) would be impossible without the synergic interaction between perception, propositional memory (especially semantic memory), and semantic imagination. We should note, however, that the role of each one of these capacities can vary depending on the type of sign structure and sign system at stake and the function they perform in a given situation. Situations which persons and groups are more accustomed to normally are represented within well-established sign structures and sign systems that demand a more preeminent role of perception and propositional memory than that of imagination and semantic imagination. Situations that have some degree of novelty and with which persons and groups recognize or fell as out of normal and challenging in some way seems to demand a more preeminent role performed by imagination and semantic imagination. In other words, the preeminent role of imagination and semantic imagination in the processes of signification is required when we are in need of generating and transforming the meaning (sense and reference) of signs and sign structures designed to give sense to situations we recognize or fell as having some degree of novelty and that challenge our habitual suppositions and expectations.

From this semiotic standpoint, we can furnish some examples of how imagination plays an indispensable semantic role in constituting the sense and reference of iconic and indexical signs and sign structures pertaining to non-discursive sign systems. For instance, in order to interpret a given painting we never see before, depicting something we do not have a direct perception or a mnemonic representation, we must construct mental images extracted from memories of similar states of affairs previously perceived so as to given a sense to the painting, identifying what this representation show us and the way it does. In the case of indexes, for instance, when we found a footprint in some route we are walking in, this means that some footed animal (human or non-human) crossed the path we are. By the features of this index, 
we can mentally depict and conjecture what kind of animal has crossed the path before us. Many other examples to see the imagination work in constructing the sense of indexical signs in relation to its possible referents could be gathered from detective stories like those written by Edgar Allan Poe, Conan Doyle, and many others. Passing to discursive sign system, a given iconic sign or sign structure (for instance, a new metaphor or a metaphor never heard or read before by someone) usually demands the work of imagination either in order to be created or to be understood in its possible meaning. Further, a given indexical sign or sign structure (an anaphoric expression referring to some possible past, present or future event, for instance) usually requires the use of imagination in order to be produced or understood in its possible meaning.

In light of this, the crucial task of the remaining part of this paper is to discuss and point out paradigmatic cases in which imagination is a necessary sense-condition for constructing and transforming the meaning of more properly symbolic sign structures and sign systems, either involving non-discursive (or semi-discursive) sign structures or involving more properly discursive sign structures. Such is needed because traditional semantics (either in philosophy or in logically oriented cognitive sciences) locates meaning exclusively at the symbolic level of sign systems, especially of discursive sign systems. On this view, the meaning is a property of the propositional content expressed by the sentences, primarily by the indicative sentences used in statements. ${ }^{32}$ Moreover, from this traditional perspective, the examples we just have seen would be considered a kind of contextual elements that should be separated from the level of the meaning attached to symbols and symbolic structures. Therefore, in order to ground the concept of semantic imagination in face of the traditional conception of semantics, we must show that imagination operates at the semantic level of symbolic sign structures and symbolic sign systems, either in symbolic structures and symbolic sign systems outside of discourse (what will both corroborate the semiotic view on the signification processes operated by us and show that the semantic function of imagination goes beyond discourse), or in symbolic structures pertaining more properly to discursive sign system (what will corroborate the concept in cases usually took into account by the traditional semantics).

To fulfill such task, I will discuss and point out the role of semantic imagination in two fields of phenomena denoted by the concepts of diagrammatic thought and counterfactual thought. In the case of diagrammatic thought, propositional content is dependent on the meaning we ascribe to the diagrammatic symbols. Given such symbols are not primarily discursive, discourse can only "manipulate" and partially translate its meaning. ${ }^{33}$ Creating, using, and translating the meaning of these abstract symbolic signs, I claim, can only be performed by the semantic imagination. To tackle more directly the core of the issue, I will briefly discuss only diagrammatic thought involved in mathematics, logic, and natural sciences, setting aside the cases 
of diagrammatic thought in the construction and understanding of the meaning of sign structures produced in non-discursive or semi-discursive arts. In the case of counterfactual thought, in which we create and deal with counterfactual scenarios, I will briefly discuss and point out the work of imagination in giving sense to the propositional content of symbolic and abstract discursive signs structures effectively operated by us. The kinds of counterfactual thought that will be briefly discussed range from the more abstract case of the meaning of modal concepts to the more concrete cases of creative discursive devices operated in dialogic and narrative discourse. ${ }^{34}$ I hope the pieces of evidence that will be raised and briefly discussed within the semiotic conceptual framework just sketched can corroborate the acceptance of the semantic role played by imagination or, at least, making it worth to be discussed.

\section{Two general fields of phenomena for evidencing semantic imagination as condition to our linguistic experience: diagrammatic and counterfactual thought}

\subsection{Semantic imagination in diagrammatic thought}

As we glimpsed before, diagrammatic thought and representation constitute a borderline field wandering between image-oriented and discursive-oriented processes of signification. If we assume that diagrams - conceived as symbolic icons and/or symbolic indexes - can express or bear in some way a propositional content, we have the first general evidence for a semantic function of imagination, that is, a function in which imagination is responsible for connecting the sense of diagrammatic signs with their possible referents.

The first philosopher that seems to have understood the role of imagination in the somewhat active construction of the geometrical figures was the Neoplatonist Proclus, who in his invaluable commentary to Euclid's Elements argues in favor of an indispensable role of the human imagination in copying the eternal mathematical forms situated in the intelligible world. His remarks suggest that imagination is a condition to our intellect (which proceeds mainly discursively) to apprehend and understand the real meaning of the intelligible figures. ${ }^{35}$

However, the semantic role of imagination is not restrained to the cases in which we deal with geometrical figures and their discursive counterparts. Other kinds of diagrammatical structures require imagination, either in its construction or in its understanding. Analytic geometry, initially developed by Descartes and Fermat, is another example. In fact, Descartes' grounding work in analytic geometry (conceived as a universal method of knowledge) makes an evident appeal to the imagination as a basic mental capacity, so as we can see in Descartes' conception of analytic geometry

Principia 21(2): 339-378 (2017). 
the semantic role of imagination into constructing and understanding the two-way transition between figures and algebraic formulas, as well as in their concrete applications to the development of scientific knowledge. ${ }^{36}$

By the way, the unification promoted by analytic geometry opens up a wide horizon within which many new diagrammatical tool systems arose in pure and applied mathematics. These diagrammatic tools are actually iconic and indexical symbols which conduced mathematical thought to a new era of development after the first decisive theoretical steps in Greek and Muslim mathematics. Through such diagrammatic tool systems, modern mathematics and mathematized sciences become able to express thoughts both about new abstract objects and about the mathematized domains of the world. It is hard to believe that the propositional content of these thoughts could have been expressed only by means of pure discursive symbols. Moreover, within this same horizon, begins also the use of iconic and indexical symbols designed to represent logical patterns of reasoning until then mostly represented through discursive signs. The first steps of this development can be chronologically recognized through Euler's diagrams, Boole's algebra, Venn's diagrams, Frege's conceptual notation, and Peirce's logic of graphs. ${ }^{37}$ Diagrammatic representations such as these can only make sense if we assume imagination as spreading out their powers as a logical and mathematical capacity closely related with reasoning. Nonetheless, among the authors just listed, Peirce was who push forwards in a systematic way a unified and comprehensive conception on both the role of diagrammatic thought and of imagination in the logical and mathematical reasoning in general. He conceives mathematical reasoning as a constant exchange between the more abstract symbolic level of discourse and the more "concrete" level of diagrammatic (iconic and indexical) symbols, an exchange in which the two levels must be regarded as mutually dependent. ${ }^{38}$

Despite the preeminence of diagrammatic representation in formal sciences, we can also see the invisible hand of imagination playing an important role in the construction and understanding of diagrammatic tools developed in many scientific fields, such as biology, geology, cartography, physics, and chemistry. Peirce's conception of the role played by diagrammatic signs across the sign systems, in fact, comes from his close contact with such diagrammatic expedients used in modern natural sciences. His conceptions of the nature of icons and indexes constitute the first groundbreaking general theory that vindicates in the field of philosophy the millenary use and development of the diagrammatic reasoning and representation in the formal and natural sciences. ${ }^{39}$

These few examples coming from mathematics, logic, and natural sciences point out to us that symbolic realm propositionally structured is wider than the common assumption according to which propositional content would be only presented or expressed in discursive forms. Diagrams, taken as symbolic images (symbolic icons and 
symbolic indexes), show us that imagination is a condition both to the very construction of the sense of these symbolic structures and to the possible rendition of the scientific use of these images in the discursive level. We can conclude, even based on the few clues here adduced, that imagination plays a vital role not only in the construction and understanding of the diagrams but in the "rendering" of these symbolic images in their possible discursive counterparts. Therefore, if we must admit that diagrammatical reasoning in pure and applied mathematics, in logic, and in natural sciences has and express a propositional content, then, at any rate, imagination must be regarded as one of the necessary conditions to construct, reconstruct, convey, and understand such a propositional content. Therefrom, diagrammatic thought (and imagination at its core) is not only a way to represent, apply or help our ways of thinking but also a way of thinking by itself. ${ }^{40}$

\subsection{Semantic imagination in counterfactual thought}

\subsubsection{Introduction: the importance, the extent, and the general role of semantic imagination in counterfactual thought}

The second field of phenomena where we can visualize the performance of semantic imagination in the level of the sense-conditions for our linguistic experience is that coming from the analysis of the logical and psychological conditions required to form and deal with counterfactual scenarios. As it is already recognized, one of these conditions is what is called counterfactual imagination. ${ }^{41}$ Nevertheless, before tackling the issue directly, some introductory words are required, given the huge importance of this field to visualize semantic imagination. From the semiotic framework here at stake, the far most important feature of counterfactual thought lies precisely in what has disquiet the philosophers that first brought the concept to light: counterfactual thought (and the logical structures in which it is framed) many times has no well-delimitated truth-conditions and sometimes has no truth-conditions at all. Within the conceptual framework here at stake, this means that discursive productions (or even semi-discursive productions using diagrammatical tools) undertaken in counterfactual thought make or do not make sense regarding several kinds of criteria, which are primarily related to sense-conditions and more specifically to coherence-conditions than to truth-conditions. ${ }^{42}$ In making or doesn't making sense counterfactual thought shows its real power, even when (and sometimes because) has not a determinate truth-value. Actually, counterfactual thought turns out to be the place where what we take as known or what we believe as true (factual) is put on suspension for a while into the unlimited atmosphere of the possible, allowing us to reflect on and evaluate such knowledge and beliefs, often leading us to know new aspects of what is factual or possible for us or for the world we live in. ${ }^{43}$

Principia 21(2): 339-378 (2017). 
Now, we can take again the thread into the labyrinth. As said earlier, I will include as instances of counterfactual thought: conceptions and application of modal concepts, thought experiments, apagogical arguments, as well as creative devices used in discourse. Up to now, however, it is only clearly recognized some kind of relation of this concept with our conceptions and applications of modal terms and in much lesser degree with thought experiments. The relation between counterfactual thought and apagogic arguments, as well as with creative devices is still scarcely admitted. ${ }^{44}$ Therefore, I must begin this section by justifying the widening of the traditional sense and extension ascribed to the concept of counterfactual. My general argumentative strategy is grounded in recognizing and distinguishing two senses (with their corresponding extensions) of the concept. The narrow sense, as assumed in the traditional position, and the wide sense, as it will be proposed here. The wide sense of the concept is quite clear by means of its etymology: 'counterfactual' means what is 'contrary to the facts'. At bottom, the big question concerning the narrow and the wide sense of the concept resides on what would be the sense of the term 'facts'. Anyway, the wide sense of counterfactual must contain the narrow sense. My claim is that counterfactual thought (and the role of imagination within it) should be understood as operating in the extension of the wide sense of counterfactual. Stated the general hypothesis, I pass to its justification.

Its origins and first unfolding determine the narrow sense of the concept. Actually, Nelson Goodman coined the term 'counterfactual' as a "translation" of Chisholm's expression 'contrary-to-fact'. ${ }^{45}$ In both authors, the notion is closely linked to the analysis of what went to be known as 'counterfactual conditionals'. The basic forms of counterfactual conditionals often fill the following logical patterns: (1) 'if a were (not) $F$, then $a$ could (not)/would (not)/should (not) be $G$ '; as well as (2) 'if $a$ were (not) $F$, and $a$ is somehow linked to $b$, then $b$ could (not)/would (not)/should (not) be $G$ '; where ' $a$ ' and ' $b$ ' can stand for proper names, defined descriptions, and quantified variables ranging over sets of individuals or even over sets of predicates. For sure, counterfactual conditionals can acquire more complex grammatical or logical forms, but these two are enough to see from which problem the concept sprang up in the contemporary theoretical landscape. Soon after analytic philosophy starts the logical analysis of the counterfactual conditionals, psychology began to realize the pervasive character of this kind of conditionals in ordinary cognitive processes, so that a vast array of researches quickly flourished under the rubric of 'counterfactual thinking'. 46

Notwithstanding the undeniable value these philosophical and psychological investigations, they see counterfactual thought as essentially restrained to the contrasting relation between the actual world and the past or present possibilities that might have been but weren't or aren't the case. Other kinds of things that can count as contrary to the facts are excluded from the scope of the concept of counterfactual. 
Such occurs because two major implicit restrictions are assumed in the understanding of counterfactual conditionals, restrictions that entail the restriction in the scope of counterfactual thought. The first restriction consists in supposing the '(not) were', inside of 'if $a$ (not) were $F$ ', should be interpreted as necessarily denoting a past or present unrealized possibility. The second restriction consists in regarding the relation between ' $a$ ' and ' $b$ ' in the type (2) as necessarily being a physical causal relation.

Against the first restriction, if we take the '(not) were' in the antecedent as being able to cover any kind of predicative attribution or denial, then not only past or present unrealized possibilities but also any other kind of temporal or timeless possibility and impossibility could be integrated into counterfactual conditionals. ${ }^{47}$ Against the second restriction, if we take the relation between ' $a$ ' and ' $b$ ' as not being only a physical causal relation but also any kind of relation (v. g., logical, mathematical, historical, psychological etc.), then we have two consequences: on one side, (i) we confirm that other kinds of temporal and even timeless possibilities and impossibilities can enter into counterfactual conditionals; and, on the other side, (ii) what could count as a fact is not restrained to physical facts, but include any kind of thing we suppose as factual. It was precisely bearing the second restriction in mind that I used the term 'somehow' in characterizing the link between ' $a$ ' and ' $b$ ', rather than a specific kind of relation. Provided with such an understanding of the counterfactual conditionals, and thus of the counterfactual thought, we can include in a proper way as instances of counterfactual thought our conceptions on modal concepts, thought experiments, apagogical arguments, and creative devices used in discourse.

In a general way, imagination is required in constructing and understanding the meaning (sense and reference) of the counterfactual scenarios because what is "depicted" in such scenarios lack a direct reference in the actual world accessible by means of the perception and registered in the episodic memory. The complex and creative work of giving sense and reference (meaning) to counterfactual scenarios can only be undertaken by the imagination in a close cooperation with propositional memory, that is, with episodic and mainly with semantic memory. As researchers in cognitive sciences recently said, semantic memory is the root of imagination. ${ }^{48}$ Such is true also to the semantic imagination as an essential condition to carry out counterfactual thoughts (and diagrammatic thoughts). Just as memory is based on perception but expands it, so imagination is based on memory but expands it. Analogously, semantic imagination, in creating counterfactual scenarios, is based on propositional (episodic and semantic) memory but expands it. Counterfactual scenarios are built upon the propositional content "stored" into propositional memory, mainly in semantic memory. It is for this that only semantic memory can record and maintain counterfactual scenarios built by imagination, not only to a given person but also to any person, provided that such scenarios come to be extended to others by the voice, by the writing or by any other extension of our mind available in the social artifices 
and artifacts structured in the sign systems we create and operate.

Moreover, the direct reference of counterfactual scenarios can only be the "material" kept saving in the propositional memory, especially in semantic memory, and only through this material can refer to the perceptual and actual world. Thus, we have a process in which counterfactual (and semantic) imagination refers primarily to the material of propositional memory and through this reference can indirectly refers to the perceptible and perceived world. Such process of indirect reference shows us the complexity of the work of imagination in creating counterfactual alternatives to the perceptible and perceived world. Once having been created, however, such scenarios can change the limits and the structure of our semantic memory, and so of our way of perceiving and acting in the world around us. Here we glimpse the complex cooperative circular way in which perception, memory, and imagination are hand in hand to constitute what above was called linguistic and semiotic experience. It seems true what Wittgenstein once said in his enigmatic Tractatus, that the limits of our world coincide with the limits of our language, though such limits are movable and one of the factors which widen them are the works of counterfactual thought, for it is not bounded to what is the case, but runs always toward the limits of the possible. ${ }^{49}$ Once summarily justified the wide sense of the counterfactual thought, we can go forward and analyze the instances of counterfactual thought above listed in order to see the semantic role of imagination in the construction and understanding the meaning in each one of these instances.

\subsubsection{Semantic imagination in our conceptions of modal concepts}

The recently widespread notion of possible worlds, whatever be its ontological status, is closely related to counterfactual thought, and thus (I believe) to the semantic imagination. Even if we regard, through traditional semantics, possible worlds as mind-independent formal structures, its application to concrete cases would be impossible without some function undertaken by imagination, once possible worlds, as formal structures, must lack any concrete reference in order to keep their pure logical form. This observation indicates that imagination must produce the sentences depicting the counterfactual scenario onto which the formal apparatus is instantiated, as well as the propositional content of these same sentences, given they can only make reference to the actual world through such and such state of affairs belonging to some or to all possible worlds. On this perspective, we should say that the purely formal semantics of possible worlds must have an "impure" psychological semantic counterpart in order to be applied to concrete "worldly" cases. There seems to be no better candidate available than counterfactual imagination to play the role of the "impure" semantic counterpart to the formal possible world semantics. Up to this point, we are within the traditional limits of the epistemology of modalities, ac-

Principia 21(2): 339-378 (2017). 
cording to which ordinary counterfactual thought is a kind of coryphaeus responsible for introducing, commenting, and explaining to the audience the actions of the syntactic and semantic modal structures described by formal modal logic. Thus, within the traditional conceptual screenplay, counterfactual imagination (and the "impure" semantics that it carries out) seems to have a warranted role on the stage, even being that of a supporting actor. ${ }^{50}$

However, if we take another path and are disposed to approximate modal semantics to modal epistemology, someway "blurring" their borders, then imagination turns out to be not only a condition to get the access to possible worlds, regarded as mind-independent abstract structures, or to apply them to particular counterfactual scenarios, but rather a pre-logical condition to "tailor" modal concepts into their formal logical fashion. ${ }^{51}$ The way we imagine or conceive the sense of modal concepts determines the way we construct the logical apparatus through which we formally grasp and symbolic reframe our pre-formal conceptions of the modal concepts. In such outlook, it seems to be only after assuming a philosophical position concerning the functions and extent of the modal concepts that the formal (logical and mathematical) framework of possible world semantics can be constructed. In other words, different conceptions of modal concepts and modal vocabulary give rise to innovations in the logical apparatus that sustains symbolically possible world semantics.

Here are some examples. Ruth Barcan Marcus' essentialist convictions on modalities gave rise to the famous Barcan Formula. Actualist convictions on possible worlds led Kripke to introduce the function domain in order to indexing individuals to a given possible world, and thus avoiding counterintuitive consequences yielded by the acceptance of the possibilia derived precisely from some applications of the Barcan Formula in certain modal systems. Lewis' nominalistic position conducted him to defend extreme modal realism and to introduce some notions in the symbolism, like the notion of counterpart relation between individuals in different possible worlds, rejecting with it at once metaphysical modal conceptions such as hacceitism, essentialism, and transworld identity. ${ }^{52}$

Such examples show us that our pre-logical conceptions about the meaning (sense and reference) of the modal concepts determine the way the concept of possible worlds is regimented in the logical apparatus. These pre-logical conceptions of the modal concepts, yet, are inconceivable without the work of imagination, given the consensual assumption that modal concepts are reached surpassing the actual states of affairs accessible in perception and memory. If imagination is the sole capacity recognized as having the power of constituting our conceptions of what was not or is not actual but might have been once and now, of what is not yet actual but can become henceforth, and even of what never is or of what is always actual; again, if imagination is such capacity, then at least part of the formal apparatus created in modal logical systems has its source in the way we conceive or imagine the meaning

Principia 21(2): 339-378 (2017). 
of modal concepts. If it is so, then the pure formal semantics seems to be (at least partially) rooted in the "impure" psychological semantics performed by imagination in creating counterfactual scenarios. The variety of positions concerning the ontological status of the possible worlds (reflected somehow in the logical apparatus set forth) seems coming from the way our imagination conceives modalities through the counterfactual scenarios created by it.

In general, my position is that counterfactual thought deals with possibilities "in the wild", showing us the space-time of our linguistic experience where we give "worldly" meaning to modal vocabulary and modal concepts, not a logically idealized meaning. Many times, even what is impossible is thought of as if it would be possible, revealing us that counterfactual thought is not bounded by the laws of logic or modal logic. Counterfactual thought deals with possibilities and impossibilities in the space between the full sense and the complete nonsense. In this perspective, this kind of thought is wider than the logical patterns established by modal logic. As we will see below, the counterfactual thought is not only vital in our everyday experience, but also philosophy and science have made important uses of the counterfactual thought, and are still doing. The power of suspending for some while what we take as factual, and thus as actual and necessarily actual, contrasting it with the merely possible or impossible, is the real wonder of counterfactual thought. After this conjectural space of conceiving (imagining) the possible senses of modal concepts we are able to constitute modal logical systems. Even being necessary to recognize the indispensability and the huge importance of formal modal logic to our clear understanding of modalities, in order to not commit the part-whole inversion fallacy, we should concede priority to counterfactual thought over formal modal logic, since counterfactual thought can be seen as a condition of possibility for constructing and understanding formal modal logic, as well as for applying it to "concrete" scenarios. Thus, on this view, semantic imagination seems more akin to a screenwriter than to a supporting actor.

\subsubsection{Semantic imagination in thought experiments}

Another instance of counterfactual use of imagination in order to give sense to the propositional and discursive structures we deal with is thought experiment. Setting aside the controversies about the explanations of this procedure and on its variety, validity, and limits, we can easily recognize that thought experiments present to us a set of propositions which are neither derivable by abstracting or by generalizing features of our sensory or mnemonic encoded experience nor are a simple application of some already existent universal conceptual schema. ${ }^{53}$ Nonetheless, the "understandability" of such a theoretical expedient is out of the question. Thought experiments show us propositions whose sense (not the reference) is not understandable without

Principia 21(2): 339-378 (2017). 
a semantic function of imagination. Thought experiments, used either to confirm or to doubt some given proposition or theory (taken as a set of ordered propositions), require we may figure out some abnormal situations that defy our sensory habits or mnemonic expectations. The champion of the most famous thought experiments, Albert Einstein, glimpsing the fundamental role of imagination, once said: "Imagination is more important than knowledge. Knowledge is limited. Imagination encircles the world" (Calaprice 2010, p.12). In fact, Einstein's prodigious capacity to conceive weird albeit perspicuous conceptual scenarios shows us that imagination plays a vital role in making sense of such theoretical devices, not only in understanding but also (and maybe primarily) in constituting them.

Yet, instead of picking up one of those thought experiments proposed in physics, let us taken in account a famous one in philosophy: the Twin Earth argument advanced by Hilary Putnam. ${ }^{54}$ At the core of this argument lies the claim that there would be a world made up almost like our, but in which water, even having the same perceptual properties of water on earth, has a different molecular constitution, say $X Y Z$. In imagining such alternative state of affairs "within" an imaginary possible world we do not need to elaborate some figure or visual image, but a propositional abstract content, in this case, a different molecular constitution of water in the hypothesized twin earth. What is imagined here is the sense or the propositional content of some "fictional sentences". For instance, "water' at Twin Earth means ' $X Y Z$ '.", "If water is $X Y Z$ at Twin Earth, then the human inhabitants of Twin Earth should be chemically different from us, even if they are apparently like us." are two among an infinite number of sentences imaginable in which no mental image should be attached to the propositional content.

Thought experiments are conceptual fictions that, even being neither true nor false in themselves, intend to guide us to what is true or false, or, at least, make us think otherwise about something. It is precisely by not being true or false in themselves that semantic imagination is a necessary sense-condition in constructing, understanding, and drawing conclusions from them. Hence, at least in part, sentences (and their propositional content) depicting and describing thought experiments scenarios force us again to admit that imagination plays a role in the sense level of these same sentences, both in order to construct and in order to understand them.

\subsubsection{Semantic imagination in apagogical arguments}

Another type of procedure in which counterfactual imagination is required is in the well-known apagogical arguments, ${ }^{55}$ in which we need construct counterfactual scenarios aiming to prove or disprove indirectly a given proposition. From Parmenides to our days, some of the most famous philosophical and metaphysical principles and concepts were proved or corroborated by means of this kind of argument. Adapt-

Principia 21(2): 339-378 (2017). 
ing to our context Rescher's proposal, apagogical arguments can be divided into two types. ${ }^{56}$ The first is the reductio ad absurdum, in which, in order to prove a given proposition, we take its contradictory as if it were true, drawing some absurd consequence in relation to a given set of propositions accepted as true or necessarily true. The second is the argument per impossibile, in which, in order to refute a given proposition, we take it as if it were true, drawing from it some impossible consequence in relation to a set of propositions accepted as true or necessarily true. The difference between them, therefore, is that reductio arguments are used to prove the truth of a given proposition by means of its contrary or contradictory, whilst per impossibile arguments are used to refute a given proposition in showing the absurd consequences resulting from its acceptance as true. The outcome in both cases is the demonstration of the opposite proposition hypothetically assumed as true in the premise. ${ }^{57}$

The role played by counterfactual imagination in this important kind of argumentation is visible in the momentary suspension of disbelief required to undertake both types of this procedure. We must briefly discuss this act of suspension. On one side, bearing a proposition in mind implies that we believe as true what is said in its propositional content, whatever way we can understand it. On the other side, however, we often came to discover that propositions we previously had believed as true are in fact false. This is a very straight description of the propositional error. Yet, we can still bear in mind a proposition we had believed erstwhile as true. We now believe that it is false, but we believe no more in what is said in its propositional content. In other words, to believe that a proposition is true entails believing in its propositional content. Nevertheless, believing a proposition as false is believing in the propositional content of a different (contradictory, contrary, or even unknown) proposition is true. Thus, we believe that a given proposition is false if and only if we don't believe in its propositional content. To bear in the mind a proposition in which we don't believe, a proposition which we actually consider as false, is only possible through imagination since only imagination can aim at a propositional content we actually don't believe in. ${ }^{58}$ Such can be made clearer by the case of the liar. The liar does not really believe in the proposition (s)he occasionally utters, even though pretending it is true when uttering the proposition to someone else, intending the other person take it as true.

What is weird in the case of apagogical arguments is that, in a certain sense, we are lying to ourselves, don't to someone else. We must pretend to believe in a propositional content we really don't believe in. During such procedure, we are twisting and reversing the normal way we believe in propositions as true. In the case of reductio arguments, we must make-believe the propositional content of the opposed (contrary or contradictory) proposition to that we want to prove. In the case of per impossibile arguments, we must make-believe the propositional content of the very proposition we want to refute. Therefore, both argumentative procedures require that we simulate believing as if it were true a false or necessarily false proposition, 
a function that seems only ascribable to the imagination. If we assume the mental capacity of taking a false or necessarily false (impossible) proposition as if it were true or necessarily true, and if the meaning of propositions included in well-ordered inferential patterns depends on its truth-value, then, in apagogical arguments, we are imaginarily changing the meaning of a proposition for the sake of the argument.

Moreover, if we need, by definition, ascribe to reason the logically structured activities of the mind, it would be odd to think the reason itself could give sense and deals with irrational or nonsensical situations, scenarios, and propositions engendered in the apagogical arguments. As in the modern classical theory of knowledge, it seems prudent resorting to a cooperation between reason (that is, logically structured mental activity) and imagination in order to explain the entire process demanded to fulfill the apagogical arguments. Thus, the role and content of the counterfactual scenarios hypothesized in such arguments cannot be explained by restraining the propositional level of the mind to reason; so as we must admit that the propositional content at stake in apagogical arguments requires a collaboration between reason and imagination, which, therefore, also can give sense and deals with propositions which we don't really believe in, just pretend to believe. Hence, apagogical arguments (and the propositional contents involved in them) can be seen as a paradigmatic case of cooperation between reason - by definition ruled by logical laws — and semantic imagination, which is not necessarily committed to logical laws, and, perhaps, to any other law.

\subsubsection{Semantic imagination in the creative discursive devices}

Finally, we can point out the semantic role of the imagination in counterfactual thought performed through creative devices found in the discourse. By the expression 'creative device' I mean here what classical tradition had called 'rhetorical figures'. Such 'figures' range over from devices operating over terms and expressions within a single sentence (usually called 'figures of speech' or 'tropes') up to those operating over types of discourse (usually called 'literary genres'), pointing towards a certain discursive attitude in speech and writing. Such devices are 'creative' because they rend available to anyone inserted in a culture the ways to give a particular sense for his/her own discursive productions and deeds, a sense that carries the mark of a personality and a context. Thus, 'creative' does not mean a creation ex nihilo of the meaning, but, as we have seen above, its emergence as the blend between the generality of the conceptual and linguistic schemes and the particularity of the contexts and aims pursued by persons and societies.

Of course, such description still presupposes that we are here talking about discourse in its usual form, as dialogue and narrative, don't of discourse in its more abstract, purified declarative form. Most of the time, traditional philosophy of lan- 
guage, and the semantics inside it consider meaning something solely objective and impersonal because declarative discourse is practically that which it takes into the account. However, everybody knows that discourse receives a physiognomy within the conceptions on life and world held and produced by people of flesh and blood. Thus, creative devices are "tools" historically constructed and available in each idiom and culture through which real people plunge their discourse in a given situation. After that, general grammar and formal semantics can analyze the discourse, dissecting it up to its bones and nerves.

From the outset, however, we should avoid the usual view according to which rhetorical figures would be mere ornaments for embellish discourse or to make it more convincing, and mostly as if they were exclusive properties of fictional literary discourses. What endows with literary status some narrative and dialogic discourses is just the degree in which the narrative features existing in everyday discourse are used, expanded, and transformed. One of the values of literature is to reveal more directly than any other way the life forms embodied in our discourse. Indeed, the phenomena named as 'rhetorical figures' pervade ordinary language, and such figures are not only linguistic procedures but are effectively cognitive processes. ${ }^{59}$ Regarded in a semiotic perspective, rhetorical figures constitute the strongest evidence for ascribing to the imagination a semantic function in the signification processes through which we constitute the meaning our discourse.$^{60}$ Contrary to a dominant view in philosophy of language, rhetorical aspects in the ordinary, literary, and even philosophical discourse cannot be simply branded as pragmatic effects that would have nothing to do and do not affect the semantic level of the discourse. ${ }^{61}$

In addition, we should not confine, as usually, rhetorical figures to the case of metaphors. Rhetorical figures, including metaphor, encompass a plethora of aspects displayed in almost every kind of discourse, aspects that have syntactic, pragmatic, and semantic levels. ${ }^{62}$ Hundreds of them were listed alongside metaphor, and they shape the physiognomy of our effective discourse. Whatever, the concept of creative discursive devices operated is a new way of considering the old phenomenon of rhetorical figures as an essential aspect of our linguistic experience. Yet, some of these figures have a more visible semantic accent than others, what explains the usual focus on metaphor as a preeminent semantic rhetorical figure, whose close relatives include metonymy, synecdoche, simile, and allegory.

As we have seen above, semantic imagination is required to explain what is called linguistic creativity. Such concept involves syntactic, pragmatic, and semantic aspects. ${ }^{63}$ For the sake of brevity, I will restrain the following considerations to its more preeminent semantic aspect, and, in addition, to the well-known rhetorical figure of metaphor. Semantic creativity is the process of generating new meaning to existing words and expressions or the meaning of new words and expressions. Again, to turn out the next lines as brief as possible, I will take the case of generation of new mean-

Principia 21(2): 339-378 (2017). 
ing to existing words and expressions. Such process can begin from the literal meaning toward a new figurative meaning, or vice-versa, from a given figurative meaning to a new literal meaning. Once more, it will be necessary to confine our attention to the first case. Thus, within linguistic creativity, we will consider its semantic aspect, applied to metaphors in creating the figurative meaning starting from a literal meaning of already existing words and expressions. Such restrictions should warn us about the real complexity of the phenomena comprised under the term 'linguistic creativity'.

In a previous paper, I have argued that the semantic function of imagination operating through some rhetorical figures could be seen under the cognitive and semiotic procedure of analogy. ${ }^{64} \mathrm{I}$ have proposed that analogical general patterns can be captured in the following schemes: (i) $A$ is for $B$ in the relation $R n$, as $B$ is for $C$ in the relation $R n$; (ii) $A$ is for $B$ in the relation $R n$, as $C$ is for $D$ in the relation $R n$. Such general schemes, I think, can explain the multitude of cognitive (and thus significant) processes through which we put in relation a source-domain and a target-domain of objects, processes that are on the basis of many rhetorical figures, especially those above indicated surrounding metaphors. What can take the place of the terms ' $A$ ', ' $B$ ', ' $C$ ', and ' $D$ ' is any domain of object denoted by anything functioning as a sign (not only discursive signs). By the symbol ' $R n$ ' is meant all possible kinds of relations we can and effectively establish between these objects or domain of objects. The index ' $n$ ' in ' $R n$ ' intends to express symbolically the fact that we usually do not only put on the objects or their domains in analogical relations but also the relations themselves. In this sense, the index filling the relation in both sides of the analogy can vary.

One example will be here enough to illustrate the process of generating figurative metaphorical meaning to given signs. When we say to someone the following possible sentences: "Please, read this book. It will be a good food for thought", "This book will nurture your mind", "This book will satisfy your hunger for new ideas", or even "Given your intellectual interests, you should devour this book", we are saying that a certain book is good for a certain "mental diet" as a certain kind of meal is good for a certain bodily diet. The relation, in such examples, is not the same, since what is meant by the term 'mental diet' is not the same as what is meant by 'bodily diet', for we suppose by 'mental diet' certain mental habits, whereas by 'body diet' certain bodily habits. Thus, we can schematize the analogy behind the metaphors this way: $A$ (a certain book) is for $B$ (a mental diet) in the relation $R a$ like $C$ (a certain meal) is for $D$ (a bodily diet) in the relation $R b$.

Now, what all this has to do with counterfactual thought and thus with counterfactual imagination? Taking the example, we can see that the analogy between books and meals presupposes we have already imaginarily considered books as if they were one kind of meal to the mind or as if they could be one kind of meal to the mind. Moreover, we could see also the following counterfactual conditionals going along

Principia 21(2): 339-378 (2017). 
with the analogical procedure 'if the mind could eat, then books could/would/should be one of its best meals', or 'what if the mind could eat, then books could have been one of its meals'. Therefore, the constitution of a new metaphorical meaning to the term 'book' in a given situation presupposes that we have made a counterfactual consideration together with the analogy between the nurture of the body and the nurture of the mind. Literally speaking, eating books is a dangerous act to our bodily diet, whereas figuratively makes a lot of sense.

What counts here as the factual, "against which" goes the counterfactual thought, is nothing else than the literal meaning of 'mind', 'eat', 'book', and 'meal'. In their respective definitions (the literal sense able to be lexicalized), books are things very different from meals, as well as 'mind' is very different from 'eat'. It would be absurd to include in a lexicon the figurative sense of books as meals to the mind, even though some figurative uses of words or figurative expression, by its recurrence, turn out to be lexicalized. We can register the sentences above mentioned in our episodic memory, but we cannot record such sentences in our semantic memory, only the general imaginary possibility of comparing books with food. This fact was precisely what led me to offer four possible sentences referring to such general possibility. Such possibility is not innate to semantic memory. It is there inseminated by semantic imagination. Long ago, someone rose up for the first time such possibility, delivering it for someone else, by means of his/her voice or by writing it, be this person a poet, a writer or some anonymous nobody. The counterfactual is here a product of our imagination, either forming the sentences or understanding them, not of our semantic memory. The factual ("literal") meaning is what counterfactual imagination changes in order to adapt it to a given context. Holding hands, the analogical and the counterfactual procedures form a symbiotic process for the generation of figurative meaning. In a general manner, linguistic creativity in its semantic aspect requires analogy and counterfactuality operated by imagination or, we can say now, by semantic imagination.

In fact, fictional literature just displays in a more noticeable and creative manner the role of the imagination in constructing the sense of the discourse in general. Nonetheless, we can visualize this overarching role in a plenty of quotidian cases coming from narratives with factual content. Companions of a voyage, for instance, can describe the same lived situations during their journey in quite different ways, that is, with different creative devices in order to emphasize different aspects of the same shared experiences. Some people amuse us because they are capable to describe otherwise boring situations with grace or humor. We admire persons that are capable to shed a new and interesting light to subjects that never have called our attention before. However, in the ordinary narrative with fictional content, we find another usual case in which the counterfactual imaginative power shows its effects upon discourse in the act of lying. As Wittgenstein indicated, at \$249 of his Philosophical Investigations: "lying is a language-game that needs to be learned like any other 
one" (Wittgenstein 2009, p.96). Yet, lying, different from other language-games, requires the inventive capacity to forge and depict more or less distant scenarios from what really occurred or actually occurs. Also different from illusion, which leads to unaware errors, lying demands an active and deliberated process of imagining and creating propositions with sense but without a real reference. That is why, in order to fulfill their intention, the liar must create propositions that can pass as true for the others. Thus, the liar has to construct propositions that can seem to have real referents, though such referents are no more than phantoms of their imagination.

In conclusion, we have seen that, far beyond being just a subjective illustrating capacity dealing only with pictures, imagination plays a very important role in making the sense of many symbolic structures ranging from the diagrammatic representations used in formal and natural sciences to everyday lies, passing through thought experiments, apagogical arguments, and both fictional and non-fictional narratives. Without the imagination, I think, all those signification processes would be impossible, that is, no one of these kinds of the thought-language-world relation could be undertaken. If this conceptual framework is correct or at least make some sense, we can say that imagination is a necessary sense-condition to at least a range of decisive intellectual and practical human activities. Even though shared with many non-human animals, in us this multiform skill gains a dimension unparalleled in the natural realm, either creating some of the utmost and outstanding works of human intelligence or becoming the principle of some of the most regrettable evils, which never were previously imagined.

\section{Acknowledgments}

I would like to thank here the comments, suggestions, and criticisms made by Gabriel Mograbi, Eduardo Piagentini, and Patrícia Fanaya when I presented the first draft of this article at 10th Principia Symposium. I would like to thank also the comments and suggestions made by the two anonymous referees on the second version of this article.

\section{References}

Abraham, A. 2016. The imaginative mind. Human Brain Mapping 37: 4197-4211.

Abraham, A.; Bubic, A. 2015. Semantic memory as the root of imagination. Frontiers in Psychology 6: 325.

Albrecht, A.; Danneberg, D. 2011. First steps toward an explication of counterfactual imagination. In: D. Birke et alii (eds.) Counterfactual thinking, counterfactual writing, pp.12-29. Berlin/Boston: De Gruyter.

Anderson, D. R. 1987. Creativity and the philosophy of C. S. Peirce. Dordrecht/Boston: Springer.

Arheim, R. 1969[1997]. Visual thinking. Berkeley/Los Angeles: California UP.

Principia 21(2): 339-378 (2017). 
Banham, G. 2005. Kant's transcendental imagination. New York: Palgrave.

Barrena, S. 2013. Reason and imagination in Charles S. Peirce. European Journal of Pragmatism and American Philosophy 5(1): 9-21.

Bergson, H. 1991. Matter and memory. Trans. Nancy M. Paul, Scott Palmer. New York: Zone Books.

Byrne, R. M. J. 2005. The rational imagination: how people create alternatives to reality. Cambridge/London: MIT Press/Bradford Books.

Calaprice, A. 2010. The ultimate quotable Einstein. Princeton/Oxford: Princeton UP.

Campos, D. G. 2009. Imagination, concentration, and generalization: Peirce on the reasoning abilities of the mathematicians. Transactions of the Charles S. Peirce Society 45(2): 135156.

Charles, A. 1971. L'imagination, miroir de l'âme selon Proclus. In: P. Hadot (ed.) Le Néoplatonisme, pp.241-251. Paris: Éditions du CNRS.

Chisholm, R. M. 1946. The contrary-to-fact conditional. Mind 55(220): 289-307.

Chomsky, N. 1965. Aspects of the theory of syntax. Cambridge: MIT Press.

Claessens, G. 2011. Imagination as self-knowledge: Kepler on Proclus' Commentary on the first Book of Euclid's Elements. Early Science and Medicine 16: 179-199.

Colapietro, V. 2003. C. S. Peirce's critique of psychologism. In: D. J (ed.) Philosophy, psychology, and psychologism, pp.157-179. New York: Kluwer.

De Almeida, N. E. 2014. Como fazer imagens com palavras: sobre a imaginação semântica a partir da poética simbolista e sua apropriação no Ulisses de Joyce. Eutomia 14(1): 488516.

— 2015. Sobre a semiótica de Heráclito e o sentido literário da filosofia. Eutomia 15(1): 234-266.

— 2016. Ligando os pontos: imaginação semântica, figuras retóricas e análise naturalista da literatura. Revista Letras 93: 337-367.

Elliott, B. 2005. Phenomenology and imagination in Husserl and Heidegger. London/New York: Routledge.

Frege, G. 1984. Thoughts; trans. Peter Geach, R. H. Stoothoff. In: G. Frege, G. Collected papers on mathematics, logic, and philosophy, pp.351-372. Brian Mcguiness (ed.). New York: Basil Blackwell.

Garavaso, P.; Vassallo, N. 2015. Frege on thinking and its epistemic significance. Lanham: Lexington Books.

Gibbs Jr., R. W. 1994. Poetics of mind: figurative thought, language, and understanding. Cambridge: Cambridge UP.

Gombrich, E. 1960[1984]. Art and illusion: a study in the psychology of pictorial representation. London: Phaidon Press.

Godden, D. M.; Griffin, N. 2009. Psychologism and the development of Russell's account of propositions. History and Philosophy of Logic 30(2): 171-186.

Goodman, N. 1947. The problem of counterfactual conditionals. The Journal of Philosophy 44(5): 113-128.

Hanks, P. 2015. Propositional content. Oxford: Oxford UP.

Husserl, E. 2001. Logical investigations (vol. 1); trans. J. N. Findlay. London/New York: Routledge.

Principia 21(2): 339-378 (2017). 
Jones, R. H. (ed.) 2016. The Routledge handbook of language and creativity. London/New York: Routledge.

Kaag, J. 2014. Thinking through the imagination: aesthetics in human cognition. New York: Fordham UP.

Kant, I. 1998. Critique of pure reason; trans. Paul Guyer, Allan Wood. Cambridge: Cambridge UP.

Kasser, J. 1999. Peirce's supposed psychologism. Transactions of the Charles S. Peirce Society 35(3): 501-526.

Kind, A. (ed.) 2016. The Routledge handbook of philosophy of imagination. London/New York: Routledge

Kosslyn, S.; Thompson, W. L.; Ganis, G. 2006. The case for mental imagery. Oxford: Oxford UP.

Klein, J. 1992. Greek mathematical thought and the origin of algebra. Trans. Eva Brann. New York: Dover.

Krämer, S.; Ljungberg, C. (eds.) 2016. Thinking with diagrams: the semiotic basis of human cognition. Boston/Berlin: De Gruyter.

Kusch, M. 1994. The criticism of Husserl's arguments against psychologism in German philosophy 1901-1920. In: L. Haaparanta (ed.) Mind, meaning, and mathematics: essays on the philosophical views of Husserl and Frege, pp.51-83. Dordrecht: Springer.

Logan, R. K. 2007. The extended mind. The emergence of language, the human mind, and culture. Toronto: Toronto UP.

Loux, M. J. (ed.) 1979. The possible and the actual: readings in the metaphysics of modality. Ithaca/London: Cornell UP.

Mandel, D. R. et alii. (eds.) 2005. The psychology of counterfactual thinking. London/New York: Routledge.

Markman, K. et alii (eds.) 2008. Handbook of imagination and mental simulation. New York/ Hove: Psychology Press.

Menary, R. (ed.) 2010. The extended mind. Cambridge/London: Bradford Books/MIT Press.

Mohanty, J. N. 2003. The concept of 'psychologism' in Frege and Husserl. In: D. Jacquette (ed.) Philosophy, psychology, and psychologism, pp.113-130. New York: Kluwer.

Novaes, C. D. 2012. Formal languages in logic: a philosophical and cognitive analysis. Cambridge: Cambridge UP.

Picardi, E. 1996. Frege's anti-psychologism. In: M. Schirn (ed.) Frege: importance and legacy, pp.307-329. Berlin/New York: De Gruyter.

Plantinga, A. 1982. The nature of necessity. Oxford: Clarendon.

Putnam, H. 1975[1997]. The meaning of 'meaning'. In: H. Putnam, Mind, language and reality: philosophical papers, v. 2, pp.215-271. Cambridge: Cambridge UP.

Rescher, N. 2007. Conditionals. London/Cambridge: Bradford Books/MIT Press.

Roese, N. J.; Olson, J. M. (eds.) 1995. What might have been: the social psychology of counterfactual thinking. London/New York: Psychology Press.

Russell, B. 2010. The philosophy of logical atomism. London/New York: Routledge.

Ryle, G. 2009. Philosophical arguments. In: G. Ryle, Collected papers, v. 2, pp.203-221. London/New York: Routledge.

Saraiva, M. M. 1970. Limagination selon Husserl. The Hague: Martinus Nijhoff.

Principia 21(2): 339-378 (2017). 
Sepper, D. L. 1996. Descartes' imagination: proportion, images, and the activity of thinking. Berkeley/London: University of California Press.

- 2013. Understanding imagination: the reason of images. Dordrecht: Springer.

Shin, S.-J. 2002. The iconic logic of Peirce's graphs. Cambridge/London: MIT Press/Bradford Books.

Short, T. A. 2007. Peirce's theory of signs. Cambridge: Cambridge UP.

Sorensen, R. 1992. Thought experiments. New York/London: Oxford UP.

Stjernfelt, F. 2007. Diagrammatology: an investigation on the borderlines of phenomenology, ontology, and semiotics. Dordrecht: Springer.

Stuart, M. T. et alii (eds.) 2017. Routledge companion to thought experiments. London/New York: Routledge.

Tiles, J. E. 1988. Iconic thought and scientific imagination. Transactions of Charles S. Peirce Society 24(2): 161-178.

Tulving, E. 1983. Elements of episodic memory. Oxford: Oxford UP.

Turner, M. 1996. The literary mind. Oxford/New York: Oxford UP.

Williamson, T. 2007. Philosophical knowledge and knowledge of counterfactuals. In: C. Beyer;

A. Burri (eds.) Philosophical knowledge: its possibility and scope, pp.89-123. Amsterdam/ New York: Rodopi.

Wittgenstein, L. 2009. Philosophical investigations. Trans. G. E. M. Anscombe; P. M. S. Hacker; J. Schulte. Sussex: Wiley-Blackwell.

NAZARENo EDUARDo DE ALMEIDA Philosophy Department

Federal University of Santa Catarina (UFSC)

BRAZIL

nazarenoeduardo@gmail.com

\section{Notes}

${ }^{1}$ On Frege's general tenets and arguments against psychologism, see Picardi (1996). For a more detailed discussion, see Garavaso and Vassallo (2015). On Husserl's arguments against psychologism in the background of its critics, see Kusch (1994). On both Frege's and Husserl's conceptions of psychologism (although more focused on the latter), see Mohanty (2003). Concerning the anti-psychologist position of the early Russell, as well as his progressive move to a more psychologist position about the nature of propositions, see Godden and Griffin (2009).

${ }^{2}$ The following passage extracted from the article "Thoughts", the first part of his Logical investigation (originally published in 1918), can shows us that Frege fuses the notion of representation or idea (Vorstellung) with the notion of image (Bild), and thus implicitly takes imagination (Einbildung) as a general feature of psychological representations: "When we ascribe truth to a picture (Bilde) we do not really mean to ascribe a property which would belong to this picture quite independently of other things; we always have in mind some 
totally different object and we want to say that the picture corresponds in some way to this object. 'My idea (Vorstellung) corresponds to Cologne Cathedral' is a sentence, and now it is a matter of the truth of this sentence. So what is improperly called the truth of pictures (Bilden) and ideas (Vorstellungen) is reduced to the truth of sentences." (Frege 1984, p.353). For a discussion of Frege's view on imagination, see Garavaso and Vassallo (2015), esp. chap.5.

${ }^{3}$ Two passages (among many others) should be quoted here to evidencing this: "Plainly therefore, considered as such, meanings do not differ essentially among themselves. Actual word-meanings are variable, often changing in a single spell of thought, by their nature mainly adjusted to the occasion. Rightly seen, however, such change in meanings is really change in the act of meaning (Schwanken des Bedeutens). In other words, the subjective acts which confer meaning on the expressions are variable, and that not merely as individuals, but, more particularly, in respect of the specific characters in which their meaning consists. But meanings themselves do not alter: this is in fact an absurd manner of speech if we adhere to our views of meanings as ideal unities, whether in the case of equivocal, subjectively defective expressions, or in the case of univocal, objectively ones." (Husserl 2001, p.224). In addition, more directly concerning imagination: "If I hear the name 'Bismarck' it makes not the slightest difference to my understanding of the word's unified meaning, whether I imagine the great man in a felt hat or coat, or in a cuirassier's uniform, or whatever pictorial representation I may adopt. It is not even of importance whether any imagery serves to illustrate my consciousness of meaning, or to enliven it less directly" (Husserl 2001, pp.228-29). For the early Husserl's concept of imagination mentioned here, see Saraiva (1970). Nonetheless, it is important to point out Husserl's early conception of imagination underwent a radical transformation some few years after the publication of the Logical investigations (1900). For an overview of Husserl's imagination conception throughout his philosophical trajectory, see Elliott (2005), chaps.1-4.

${ }^{4}$ I think my proposal is compatible with Russell's mature position about the psychological aspects required to construct a theory of meaning. It is worth to quote a passage extracted from his Philosophy of logical atomism (originally delivered as a series of conferences in 1918), which points out to the same goal pursued in this article: "I think that the notion of meaning is always more or less psychological, and that it is not possible to get a pure logical theory of meaning, nor therefore of symbolism. I think that it is of the very essence of the explanation of what you mean by a symbol to take account of such things as knowing, of cognitive relations, and probably also of association. At any rate I am pretty clear that the theory of symbolism and the use of symbolism is not a thing that can be explained in pure logic without taking account of the various cognitive relations that you may have to things." (Russell 2010, p.12).

${ }^{5}$ As I will introduce the concept of semantic imagination through a particular appropriation of Peirce's semiotics, it is important here to remember that Peirce also criticizes the nineteenth-century attempts to reduce logical and mathematical structures to psychological laws. Nevertheless, his critique of these attempts does not lead him to engage in the global anti-psychologism concerning meaning like Frege and the early Husserl. Roughly speaking, for Peirce, the abstract and universal realm of mathematical and logical laws and structures is not derivable from or reducible to psychology. Rather, these domains are complementary. On Peirce's criticism of the psychologism (slightly contrasted with those of Frege and Husserl), see Kasser (1999). For a more comprehensive evaluation of Peirce's position on psychologism, see Colapietro (2003).

Principia 21(2): 339-378 (2017). 


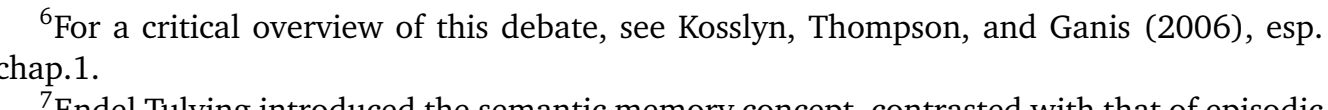

${ }^{7}$ Endel Tulving introduced the semantic memory concept, contrasted with that of episodic memory, in an article published in 1972. Yet, it was only in his influential Elements of episodic memory that the concept received an extensive treatment. See Tulving (1983), esp. part 1. Tulving classifies semantic memory, along with episodic memory, as a kind of propositional memory. While semantic memory encodes conceptual systems, which make possible discourse as well as other kinds of abstract thought, episodic memory is responsible for keeping the events and situations that take place in the time life of its "owner", a process involving language and pointing to autobiographical memory, which involves narrative devices. Propositional memory is contrasted with procedural memory, whose function is to encode and maintain our sensory-motor skills. However, as any other good empirical researcher, Tulving makes clear that we must assume such distinctions in a heuristic and methodological sense, given that in real life these kinds of memory are all blended and articulated with each other.

${ }^{8}$ It is worth to notice that Peirce's philosophy begins with a critique of the Cartesian model of mind and language, a starting-point he never had abandon across his intellectual trajectory. By this reason, I believe Peirce's semiotics has a kind of "elective affinity" with the antiCartesian program just mentioned.

${ }^{9}$ I made a first presentation of the concept of semantic imagination in two published articles written in Portuguese. See De Almeida $(2014 ; 2016)$. In the first article, I had proposed the concept connected to an analysis of the Symbolists poetics and mostly through an analysis of some aspects of James Joyce's Ulysses, mainly using Dretske's theory on "semantization" of the flow of information conjoined with some tenets and concepts of Peirce's semiotics. In the second article, I proposed the concept through a semiotic rehabilitation of the rhetorical figures as conceptual and analogical devices that exhibit the semantic work of imagination over the semantic content encoded in semantic memory, so as creating and understanding the figurative sense of terms, sentences, and discourses; and, for this reason, explaining the source of semantic changes in our discourse.

${ }^{10} \mathrm{~A}$ recent proposal, hypothesizing semantic memory as the root of imagination and exhorting to further research in this direction can be found in Abraham and Bubic (2015). An attempt to classify the many functions of imaginations in a unified cognitive model is proposed in Abraham (2016). For the researches on several aspects of the imagination and mental simulation in the field of cognitive sciences, see Markman et alii (2008). For a survey about the researches on imagination, conjoining contributions coming from philosophy and cognitive sciences, see Kind (2016).

${ }^{11}$ Henceforth, I will use also the nominalized expression 'the thought-language-world relation'. Such expression indicates that the relation at stake must be viewed as a transcendental relation, and don't as relation "between things". This is so either because the relation itself has priority over its components or because it is neither identifiable with an internal relation (as it is assumed in idealist or anti-realist positions) nor with an external relation (as it is assumed in realist positions). 'Transcendental' means here: the relation is the condition of any internal or external relation between thought, language, and world. Hence, we should not take for granted some specific sense(s) of these concepts in order to explain the relation. In an analogy with the logical conception of relations, 'thought', 'language', and 'world' could be taken as if they were variables-types filled by many different token-concepts according to the

Principia 21(2): 339-378 (2017). 
instances in which this relation takes place. In light of such analogy, these concepts should be viewed primarily as "symbolic concepts".

${ }^{12}$ It is important to say that I am not making some kind of comment or exegetical explanation of Peirce's philosophy and semiotics. I see my efforts and attempts as a development of Peirce's philosophy and semiotics in a particular direction, using them to constitute a more suitable and comprehensive model for understanding and investigating the thoughtlanguage-world relation, as well as putting them in dialogue with other several fields and issues coming from philosophy, art, and science which rose up after Peirce's life. I believe we can pay tribute to a thinker absorbing and developing his thought and not only by undertaking the important task of commenting his works.

${ }^{13}$ Such remark is necessary because the notion of semiosis is applied not only in investigations on the signifying processes between humans and their environment but also in researches about significant processes pertaining to living being in general, what is now called 'biosemiotics'.

${ }^{14}$ The notion of 'life forms' is extracted from the second Wittgenstein's conception of language-games, as is expressed in the well-known passage: "The word "language-game" is used here to emphasize that the speaking of language is part of an activity, or a form of life." (Wittgenstein 2009, p.15 (§23)). Inserted in our semiotic framework, the notion of life forms must be viewed as always escorted by a world conception, and the notion of language-games must be regarded as being applicable to any sign system and not only to discourse, even though I think Wittgenstein insinuates in some places of his famous work that there are language-games that are not completely constituted by words.

${ }^{15}$ Contrasted with the concepts of truth-values and truth-conditions, one important feature of the concept of making or having sense is that it is a concept of degree, and is more close to the alternatives already existent to truth-conditional approach to meaning, that is, to felicityconditions and (in a lesser degree) to assertability-conditions, even though sense-conditions should be regarded as wider than such "relatives". Thus, in a decreasing order of "grounding" wideness in signification processes in general, we first have to fill the sense-conditions, and then felicity-conditions, assertability-conditions, and truth-conditions. Yet, I cannot enter into the discussion of this issue in this article. Roughly speaking, something can make or have more or less sense, while something that can be true or false (whatever could count as a bearer or primary bearer of a truth-value) is not a matter of degree. Thus, usually, what can have (some/a) sense or make sense is situated between the level of the full and ideal sense and the level of the complete nonsense. Another issue that I cannot discuss here is the fact that something can have a/some sense even not currently make sense to someone. Such is visible, for instance, in the case of encrypted messages, which have some/a sense but demand a process of decryption to actually make sense to someone. Therefore, the notion of 'having (some/a) sense' seems to be wider than the notion of 'making sense', so as that anything that makes sense really has (some/a) sense, but something that has (some/a) sense does not necessarily make sense to someone. In this paper, I will use both notions as indicating the core conceptual structures which underlie the concept of signification, setting aside the differences between 'making sense' and 'having (some/a) sense'.

${ }^{16}$ Despite this idea, as far as I know, was not yet investigated, we found traces of it across the history of philosophy and science. Few but eloquent examples will suffice. The discussion of the proper form of a statement in Plato's Sophist, just before his proposal for a definition

Principia 21(2): 339-378 (2017). 
of truth and falsity. Aristotle's exigence, at Metaphysics IV 4, that the opponent of the principle of non-contradiction must say something with a given sense to himself and to whom (s)he is discussing, regardless of its truth or falsity. Husserl's exposition of the concepts of 'nonsense' (Widersinn) and 'senselessness' (Unsinn) in the fourth of his Logical investigations, within the context of his proposal of a pure grammar. Wittgenstein's use of the conceptual adjectives 'senseless' (unsinnig) and 'sense-lacking' (sinnlos) in his attempt to establish the limits of what can be thought in his Tractatus logico-philosophicus. Carnap's claim according to which metaphysical sentences are senseless because they cannot bear a truth-value or have an expressive value. Chomsky's discussion on the general condition of what he calls 'grammaticality' of a language. Another example is found in the syntactic rules at the basis of every logical and mathematical formal system, rules designed to generate and identify wellformed formulas. Such examples show that what is here proposed has certain antecedents, even though in all these moments the concept of making or having sense was underestimated in detriment of the concept of truth.

${ }^{17}$ The anti-psychologist arguments elaborated in the context of the theories of meaning mentioned in the first section of this article stem from this traditional model on the thoughtlanguage-world relation.

${ }^{18}$ I will use in this text the adjective 'discursive' slightly different from its customary sense (as a kind of speech or writing more or less digressive or prolix), denoting by means of it everything related to discourse, that is, everything pertaining indifferently to writing and speech. Accordingly, I will employ here the term 'discourse' to encompass both talking and writing, setting aside the differences between them. Moreover, I use de term 'discourse' to mean all kinds of discourse, beginning with the more basic and usual forms, dialogue and narrative, and not, as in the traditional view, sentences in the indicative mode, or statements.

${ }^{19}$ In picking up perception, memory, and imagination among the wide, variable, and fuzzy family of mental concepts displayed in our mental vocabulary, I am indicating that these three are the core of our thought activities. I cannot discuss such hypothesis here. Just for the sake of an indication, such hypothesis is based on the argument according to which if we get off any one of these three psychosomatic capacities we simply would not have conditions to conceive the activity of any other recognized mental capacities. I will set aside in this text the question on whether we should include the reason (or intelligence) alongside perception, memory, and imagination as a core mental capacity demanded to explain the concept of thought. My argument to this apparently odd exclusion is that we recognize to have 'irrational thoughts', so that reason seems to be more a set of ideal patterns of thought than a single "monolithic" capacity. In its more commonsensical sense, I suppose here that linguistic experience is permeated by rational patterns historically established and revisable; otherwise, the quarrels over such patterns among different cultures would be unexplainable.

${ }^{20}$ Henri Bergson, in his groundbreaking book Matter and memory (originally published in 1896), brilliantly argued for the intimate cooperation between perception and memory, based upon an innovative conception of perception as an active and selective process closely related with our future-oriented action plans inside the environment we live in. Likewise, Bergson has introduced the widespread distinction between habitude-memory and remembering-memory, both in philosophy and psychology. In a certain sense, my proposal can be seen as widening his arguments towards a cooperation involving perception, memory, and imagination within a semiotic framework. See Bergson (1991).

Principia 21(2): 339-378 (2017). 
${ }^{21}$ Imagination plays an important role in Peirce's philosophy, and not only in his semiotics. However, what follows do not intend to be a commentary of his works, but a development of some of the tenets and concepts of his semiotics, integrating them with contemporary developments of the new theoretical horizon of the mind, language, and cognition above mentioned. For a comprehensive account of the central role played by imagination in Peirce's conception of creativity in abduction (both in science and art), see Anderson (1987). For an overview of the concept of imagination in Peirce's philosophy, see Barrena (2013). For a more broad investigation of imagination based upon Peirce's philosophy, see Kaag (2014).

${ }^{22}$ Even taking into account empirical research, I will not assume the concept in its strict cognitive sense. Rather, my purpose is to develop a semiotic and philosophical counterpart of it. So regarded, semantic memory can be characterized as a part of human memory whose function is to maintain the conceptual schemes, through which we can apprehend, apply, understand, and enhance the sign systems that make possible our interactive processes of signification with ourselves, with other human beings, and with the historical and natural world we inhabit in. At the very core of the sign systems encoded in and decoded by semantic memory, we have discourse as the more usual sign system through which we convey the propositional content "stored" in the semantic memory. In spite of that, semantic memory also encodes other sign systems, particularly those pertaining to mathematics, systems that we can only partially express or paraphrase in a discursive form. Mathematical sign systems encoded in or decoded by semantic memory provide us with the evidence that the semantic contribution of memory in generating and maintaining the meaning of the propositional contents goes beyond discourse.

${ }^{23}$ Looking closely at the effective discourse, as that amalgam of particularity and generality, there is neither pure particularity nor pure generality. Such concepts are only useful as theoretical fictions with which we can analyze the outstanding character of our linguistic experience.

${ }^{24}$ I will leave open here the complex question on the relation between conceptual schemes and the grammatical rules and structures through which we apply and adapt such schemes to the so to say "raw material" of perceptual situations filtered by the practical aims we put to ourselves as individuals and as groups. However, it is important to emphasize that I do not believe we could extract from a given set of grammatical rules in vigor what some people call 'common-sense ontology'. Such refusal is due to the view embedded in the present perspective according to which the conceptual schemes we apply to give sense to our life forms and to our world are not immutable. Further, we do not also should regard our conceptual schemes as if they were neutral, but as being embedded and laden on our conceptions on life and world. Anyway, even being the way we frame our conceptual schemes and conceptions, and thus being in some way determined by these same conceptual schemes and conceptions, grammatical rules and structures in vigor in our discursive sign systems should be regarded as being able to frame many different conceptual schemes and conceptions. In other words, grammatical rules and structures are altered in a different way from that of conceptual schemes and conceptions indeed alter, even such discursive change being also determined by the conceptual schemes and conceptions we effectively hold.

${ }^{25}$ These variable extent and widening of semantic memory ranging from individual to collective life forms (through spoken and written languages, as well as through social artifacts and artifices) are currently beginning to be investigated through the notion of extended mind.

Principia 21(2): 339-378 (2017). 
For the discussion of several perspectives on the notion of extended mind, see Menary (2010), Logan (2007).

${ }^{26}$ Chomsky explicitly introduced the concept of linguistic creativity in a syntactical way. See Chomsky (1965). After this introduction, however, the concept has been discussed in several other perspectives. For a survey of these perspectives, see Jones (2016).

${ }^{27}$ It is important to emphasize that perception cannot perform this task without the help of semantic memory. Such observation permits us to stress that we cannot talk about a semantic perception. Rather, the semantic contribution afforded by perception is always guided by semantic memory and, as is here suggested, by semantic imagination. However, in order to discuss this issue properly, it would be necessary to enter into the debate about whether or not perception can be counted as one of the propositional attitudes, what cannot be made here.

${ }^{28}$ Kant, in his Critique of pure reason, already attributes to what he called productive imagination (differentiated from reproductive imagination) the role of linking the universal and necessary categories of the understanding with the particular and contingent stuff furnished by sensation. Such a role is described in his doctrine of the schematism. However, different from Kant, we assume here neither that the categories of understanding are immutable nor that perception would be an essentially passive faculty. Another important difference consists in the almost full absence of concern of Kant with the problem of language, so as his concept of experience just in few of its features could be matched with the concept of linguistic experience here at stake. Notwithstanding, it is interesting to see that one of the few moments where Kant speaks of the concept of meaning or signification (Bedeutung) is precisely in the context of his expositions of the doctrine of the schematism. The following passage is worth to be quoted (A 146/B 185): "Thus the schemata of the concepts of pure understanding are the true and sole conditions for providing them with a relation to objects, thus significance, and hence the categories are in the end of none but a possible empirical use, since they merely serve to subject appearances to general rules of synthesis through grounds of an a priori unity (on account of the necessary unification of all consciousness in an original apperception), and thereby to make them fit for a thoroughgoing connection in one experience" (Kant 1998, p.276). For a contemporary and comprehensive approach to the functions of imagination in the Critique of pure reason, see Banham (2005).

${ }^{29}$ In contrast with traditional philosophy of logic and language, Peirce's semiotics puts as one of its central tasks the explanation of how signs acquire different senses and different references, giving rise to new signs and new sign systems. For a survey of Peirce's semiotic theory of semiotic change (both concerning to discursive and non-discursive sign systems), see Short (2007), esp. chap.10.

${ }^{30}$ Peirce's classification of signs is more complex than that, as well as open to several interpretive controversies. I will leave this issue open. For a balanced presentation and discussion, see Short (2007), chaps.8-9. Nevertheless, even in light of this first approximation, we can notice that traditional semantics restrains itself almost completely to the level of symbolic signs, and again, at this level, restrains itself to discourse, and within the domain of the discourse focuses on indicative sentences and statements, and thus on the truth-functional discourse. Yet, as we will see below, if we can ascribe a semantic function to the imagination, this function necessarily pass through symbolic sign systems that are not confined to discourse, but also make use of sign systems constituted by iconic and indexical symbols, systems that

Principia 21(2): 339-378 (2017). 
recently were called diagrammatic thought. Further, in the case of the discourse, beyond its intertwining with other sign systems, the role of imagination in constituting the meaning of our discursive acts and deeds is more visible in those aspects usually called rhetorical, aspects that are more noticeable in dialogic and narrative discourses than in declarative ones, which, ideally conceived, must exclude from its syntactic, semantic, and pragmatic structure all the contextual, indexical, and figurative aspects existing in the ordinary language.

${ }^{31}$ The proviso 'at its morphological level' warns us that, at more complex syntactic and stylistic levels, entire pieces of discourse can exhibit an iconic character (as, for instance, in the case of allegorical discourses like fables, parables, and poems) or an indexical character (as, for instance, in the case of political and journalistic discourses). Traditional philosophy of language has already analyzed the indexical uses of entire sentences, particularly after Kaplan's influential approach to such uses. Discourses exhibiting a more symbolic character are usually those pertaining to theoretical sciences and some kinds of philosophical discourse. Another issue, however, is that of literary philosophies or literary philosophical works, in which iconic and indexical features of discourse are abundantly used. I discussed this issue in an article analyzing Heraclitus' fragments, showing that the usually considered literary aspects manifested in them should be not ruled out of a full understanding of their argumentative aspects. See de Almeida (2015).

${ }^{32}$ I think what is called propositional content - the meaning-type sameness of some conceptual unity expressed through meaningful innumerable sign-tokens - has two different senses which should not be confused. In one sense, the effective content of a propositional structure is the outcome of an a posteriori abstraction and/or generalization procedure over effective assertive acts made through sign systems, especially the discursive sign system. In other sense, propositional content is an a priori presupposition inherent to sign systems in which assertions on the nature of some object domain can be and are made. From this standpoint, the type-sameness of the propositional content across its token-expressions is dependent not only upon logical but also upon the biological, psychological, and historical patterns which rule the diversity of kinds of the thought-language-world relation we perform. Such conception is diametrically opposed to Frege's conception of propositional content, for whom propositional content should be situated in a third realm beyond the physical and the psychic. In addition, as it is visible in these conceptual considerations, I believe meaningful structures from symbolic sign systems other than discourse can be seen as having a propositional content, as I will pinpoint below. A conception of propositional content somewhat akin to this one is that presented by Peter Hanks, in straight opposition to the Fregean conception. According to him, propositions are sentence-types (with innumerable tokens) necessarily linked to the acts of predication in their relation to the nature of the objects that are aimed at by such acts. Hanks, however, partakes the traditional view according to which only discursive signs would have propositional content, as well as the presupposition that the sameness of the propositional content would be an a priori feature of these acts of predication. See Hanks (2015).

${ }^{33}$ Catarina D. Novaes proposed a very interesting view on the nature of the formal sign systems developed in logic and mathematics. In Novaes' outlook, formal systems are not an abstract form of our discursive sign systems, especially the oral discursive sign system. Aligned with the recent idea of extended mind, her conception sets forth the formal systems as conceptual technological artifacts, which extend, enhance, and (many times) correct our

Principia 21(2): 339-378 (2017). 
cognitive capacities, especially through the development of the powers pertaining to the written systems. Therefore, formal systems are not, as in the traditional way of conceiving them, some kind of bone depiction of the discourse's body, but a complementary (and somewhat independent) extension of it. See Novaes (2012).

${ }^{34}$ However, it must be stressed here that the more abstract cases of counterfactual thought, as well as the examples of diagrammatic thought coming from formal and natural sciences, are not separated from our everyday processes of signification, but only extend and deepen such quotidian uses of both types of thought.

${ }^{35}$ On Proclus' conception of active and productive imagination in his philosophy in general, in his philosophy of mathematics, and in his further reception in the history of science, see Charles (1971); Claessens (2011).

${ }^{36}$ On the pivotal role played by imagination in Descartes' philosophy of mathematics (particularly in the philosophical and conceptual basis of his analytic geometry), see Seeper (1996), pp.182-193. It is convenient here to quote an interesting passage from another book by the same author: "The conventional "truth" that Descartes mathematized thought impedes our access to a deeper truth. The mathematics he invented, analytic geometry, the unification of geometry and algebra, was the most rigorous and active use of the imagination ever conceived." (Seeper 2013, p.269). Another perspicuous analysis of the role of imagination in Descartes' philosophy of mathematics can be found in Klein (1992), pp.198-211.

${ }^{37}$ For a comprehensive approach of Peirce's logic of graphs, see Shin (2002).

${ }^{38} \mathrm{On}$ the role of imagination in mathematical reasoning according to Peirce, see Campos (2009).

${ }^{39}$ A detailed discussion and development of Peirce's forerunner proposals on the diagrammatical representation and reasoning can be found in Tiles (1988), Stjernfelt (2007), Krämer and Ljungberg (2016).

${ }^{40}$ I have limited myself here to the treatment of diagrams in the formal and natural sciences to show that this kind of symbolic signs is not confined to the arts, as is usually supposed. Yet, an analysis of the diagrammatic thought operated in the arts would require, at least, an entire article in order to be suitably discussed. A pioneering work on diagrammatic thought (conceived as visual thinking) related with our experience of the artworks can be found in Arheim (1969[1997]). For a groundbreaking study on diagrammatic thought in pictorial arts, see Gombrich (1960[1984]).

${ }^{41}$ I call 'counterfactual scenarios' every kind of meaningful structure depicting situations not given in the actual or factual world, either by means of the discourse or by means of diagrammatic symbols blended with discursive signs. The relation between counterfactual scenarios and the actual or factual world, however, can take place in innumerable ways, ranging from a close truth-oriented relation (like in scientific models) to a distant one, departed from any truth-orientation (like in highly fictional literary narratives). For a broad and groundbreaking approach to the counterfactual imagination (conjoined with rational thought patterns) from a general cognitive point of view, see Byrne (2005). Byrne's work, however, touches the theme in a different way than that I will propose here. An attempt to explain the counterfactual imagination, in my view still insufficient, can be found in Albrecht and Danneberg (2011).

${ }^{42}$ This line of thought converges with Nicholas Rescher's epistemological treatment of counterfactual conditionals. Such kind of approach intends to be an alternative treatment to those 
based in possible world semantics. Accordingly, truth in counterfactual conditionals (the logical structures that exhibit counterfactual thought) is not a matter of correspondence with the actual world or with any possible world, but is a matter of coherence or consistent preservation of our systems of beliefs. See Rescher (2007). Applying the concept of making or have sense to counterfactual thought means to give a semiotic basis to the view defended by Rescher. What is here called 'coherence-conditions' encompass several types of criteria ranging from grammatical and logical criteria to social and cultural criteria. 'Coherenceconditions' are an especial case of 'sense-conditions' designed to evaluate in epistemic contexts the acceptability of a given discursive production concerning its soundness or pertinence.

${ }^{43}$ I will not discuss here, for the sake of brevity, the approaches of counterfactual conditionals via possible world semantics, as those initially made by Robert Stalnaker and David Lewis. My position, as just mentioned, is inclined to the epistemological treatment of counterfactual conditionals made by Nicholas Rescher.

${ }^{44}$ In spite of this, Nicholas Rescher, in his epistemological treatment of conditionals, includes apagogical arguments as closely related with counterfactual conditionals. See Rescher (2007), esp. chap.14. As far as I know, there is not yet a clear approximation between counterfactual thought and creative discursive devices, even though there is some approaches on the relation between counterfactual thought, fiction, and literature.

${ }^{45}$ Chisholm's article mostly intends to expound the problem embedded in counterfactual conditionals, that is, such kind of conditionals does not have defined truth-condition. Chisholm's proposal is to convert the (explicit or implicit) subjunctive mood in which this kind of conditionals is expressed into an indicative one, in which truth-conditions would be available. Goodman's paper, otherwise, intends to widening and deepening the problem in the contexts of formal epistemology and philosophy of science, pointing out some necessary criteria to solve it. See Chisholm (1946), Goodman (1947).

${ }^{46}$ The first important survey on these researches is found in Roese and Olson (1995). A more recent survey can be found in Mandel et alii (2005).

${ }^{47}$ Despite the 'were' had a tendency to point to a past situation, it quite clear that it is not restricted to past situations or even to temporal situation at all.

${ }^{48}$ See Abraham and Bubic (2015).

${ }^{49} \mathrm{An}$ archaic testimony of this power of the counterfactual thought is already implicitly found out into a maxim attributed to Thales of Miletus by Diogenes Laertius: "The fastest is the thought (nous) because it runs towards everything".

${ }^{50}$ Alvin Plantinga presents the idea of an "impure" semantics under the names 'applied semantics' or 'depraved semantics' as a necessary level to apply in natural language and concrete cases the purely formal possible world semantics developed in Kripke's style. See Plantinga (1982), p.126 ff.

${ }^{51}$ Timothy Williamson elaborated a proposal that goes in an analogous direction. According to him, metaphysical or logical modalities should be defined by means of counterfactual conditionals and not the other way around, as in the more traditional view derived from Robert Stalker's and David Lewis' works on counterfactuals. Thus, the epistemology of modalities should be a special case of the epistemology of counterfactuals. Accordingly, counterfactual imagination would be prior and wider than the conceivability related directly to modal propositions. Nonetheless, Williamson's proposal remains essentially epistemological, 
leaving possible world semantics untouched, even raising doubts on the usual supposition of a sharp distinction between the imaginative level of counterfactuals and the logical level of modalities. See Williamson (2007). Anyway, what I am attempting here is to take a step forwards in suggesting that if the logical modalities are grounded in counterfactual scenarios (and not the inverse), then the "impure" semantics performed by imagination in creating such scenarios can "affects" the way we construct purely formal semantics of possible world.

${ }^{52}$ An already classical book collecting important exemplars of the "rich fauna" of conceptions on modal concepts can be found in Loux (1979).

${ }^{53}$ For a comprehensive and interesting approach on the structure, extent, and limits of thought experiments, see Sorensen (1992). For an overview on several aspects of thought experiments, see Stuart et alii (2017).

${ }^{54}$ See Putnam (1975)[1997]. Putnam's main purpose with this thought experiment is to undermine the verificationist conception on meaning, which, according to Putnam, is summed up in the maxim "meaning is in the head". I am in agreement with Putnam criticism, but do not think that meaning is in the world. In the semiotic framework here at stake, meaning is in the two-way road between mind and world, a road paved by our sign systems, especially discursive sign systems; a position, I suspect, that can be found in Peirce's view on meaning (sense and reference) of any sign and sign system as an essentially inferential process. According to this approach, we can neither assume the reference as a function of the sense (as the Fregean semantics indicates) nor sense as a function of reference (as the Russellian semantics indicates). Moreover, I think Putnam's posterior adherence to pragmatism goes in a similar direction.

${ }^{55}$ Notwithstanding its fabulous history in philosophy and science, as far as I know, apagogical arguments do not have yet a comprehensive and systematic historical treatment. The best approaches, again as far as I know, are that made by Gylbert Ryle and Nicholas Rescher. Ryle, with his characteristic style, points out that philosophy is basically made by means of apagogical arguments applied to the clarification of general and polysemous concepts or propositions. See Ryle (2009). The importance of Rescher's treatment, as will be see, is to show that apagogical arguments are cases of counterfactual thought.

${ }^{56}$ See Rescher (2007), chap.14. Although, what is here proposed is only inspired by Rescher's distinction, not a quotation of it.

${ }^{57}$ Such brief description, however, does not make justice to the real variety of cases and forms through which apagogical arguments took place in the history of philosophy and science. The present description is a sort of "counterfactual description" when put in face of the real complexity found in the history of this kind of argumentation.

${ }^{58}$ Aristotle already has briefly suggested, in his groundbreaking treatise On the soul (Book III, chap. 3, 427b 21-26), that only imagination (differing from the majority of other mental capacities) can present us situations we don't believe; as, for instance, frightening situation in face of which we don't few afraid insofar as they are just imagined.

${ }^{59}$ Recent authors (actuating in the fields of philosophy, psychology, linguistics, and literary criticism), grouped under what is currently called cognitive poetics, emphasize the processes exhibited standardly in the classical literature are in fact processes beginning with and sharing the general patterns ruling our everyday linguistic experience. Pioneering works on that perspective, open by George Lakoff's and Mark Johnson's works about the role of metaphors in language and thought, can be found in Gibbs Jr. (1994), and Turner (1996).

Principia 21(2): 339-378 (2017). 
${ }^{60}$ See De Almeida $(2014 ; 2015 ; 2016)$.

${ }^{61} \mathrm{~A}$ similar criticism on the traditional classification of the rhetorical figures as simply pragmatic effects, which would be outside the domain of semantics, can be found in Gibbs Jr. (1994), esp. chap. 3.

${ }^{62} \mathrm{By}$ the way, literary discourse should not be taken here as a well-definite genre including only the works belonging to literature in its popular sense. Depending on our conceptual cut, philosophical, religious, scientific, and even technical writings can count as literary discourse. 'Literary' is more an aspect or mood of discourse than a well defined kind of texts.

${ }^{63}$ Such division should be taken more as a heuristic and methodological than a "real" one because changes in syntactic structures are always accompanied by semantic and pragmatic changes. Roughly, the same applies to semantic and pragmatic changes. It is true that syntactic aspects seem to be the more durable aspects in a discursive sign system, but to see them as immutable would be inacceptable, given the diversity of syntactical patterns exhibited in historical discursive sign systems recorded. Just in artificial and formal languages syntax should be regarded as rigid. In this line of thought, we can see that pragmatic aspects are the more variable, given the diversity of purposes people use discourse. Between the more fixed syntactic aspects and the more variable pragmatic ones, semantic aspects are at an intermediary level of change in discursive sign systems, given the necessity of an average stability required for communication, a middle level between the general "emptiness" of syntax and the particular "fullness" of pragmatic contexts and aims. Anyway, syntactic, semantic, and pragmatic changes are really intertwined and can just be discerned into idealized theoretical and conceptual scenarios, which, for such reason, have always some counterfactual degree in face of the factual life of discursive systems operated by the human beings throughout history.

${ }^{64}$ See De Almeida (2016).

Principia 21(2): 339-378 (2017). 